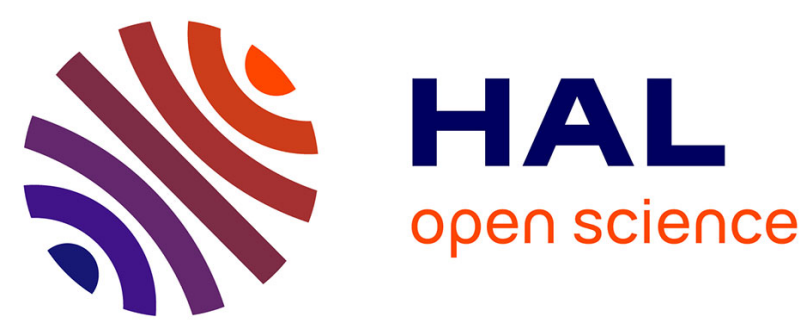

\title{
Crystal structures of oxime-bound fenamiphos-acetylcholinesterases: reactivation involving flipping of the His447 ring to form a reactive Glu334-His447-Oxime triad
}

Andreas Hörnberg, Elisabet Artursson, Rikard Wärme, Yuan-Ping Pang, Fredrik Ekström

\section{To cite this version:}

Andreas Hörnberg, Elisabet Artursson, Rikard Wärme, Yuan-Ping Pang, Fredrik Ekström. Crystal structures of oxime-bound fenamiphos-acetylcholinesterases: reactivation involving flipping of the His447 ring to form a reactive Glu334-His447-Oxime triad. Biochemical Pharmacology, 2009, 79 (3), pp.507. 10.1016/j.bcp.2009.08.027 . hal-00538094

\author{
HAL Id: hal-00538094 \\ https://hal.science/hal-00538094
}

Submitted on 21 Nov 2010

HAL is a multi-disciplinary open access archive for the deposit and dissemination of scientific research documents, whether they are published or not. The documents may come from teaching and research institutions in France or abroad, or from public or private research centers.
L'archive ouverte pluridisciplinaire HAL, est destinée au dépôt et à la diffusion de documents scientifiques de niveau recherche, publiés ou non, émanant des établissements d'enseignement et de recherche français ou étrangers, des laboratoires publics ou privés. 


\section{Accepted Manuscript}

Title: Crystal structures of oxime-bound fenamiphos-acetylcholinesterases: reactivation involving flipping of the His447 ring to form a reactive Glu334-His447-Oxime triad

Authors: Andreas Hörnberg, Elisabet Artursson, Rikard

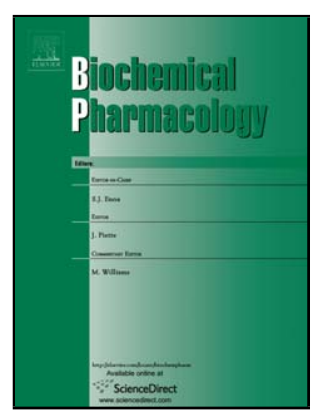

Wärme, Yuan-Ping Pang, Fredrik Ekström

PII:

S0006-2952(09)00730-8

DOI: doi:10.1016/j.bcp.2009.08.027

Reference: BCP 10311

To appear in: $\quad B C P$

Received date: $\quad$ 1-7-2009

Revised date: 26-8-2009

Accepted date: $\quad$ 27-8-2009

Please cite this article as: Hörnberg A, Artursson E, Wärme R, Pang Y-P, Ekström F, Crystal structures of oxime-bound fenamiphos-acetylcholinesterases: reactivation involving flipping of the His447 ring to form a reactive Glu334-His447-Oxime triad, Biochemical Pharmacology (2008), doi:10.1016/j.bcp.2009.08.027

This is a PDF file of an unedited manuscript that has been accepted for publication. As a service to our customers we are providing this early version of the manuscript. The manuscript will undergo copyediting, typesetting, and review of the resulting proof before it is published in its final form. Please note that during the production process errors may be discovered which could affect the content, and all legal disclaimers that apply to the journal pertain. 


\section{Crystal structures of oxime-bound fenamiphos-acetylcholinesterases: reactivation involving flipping of the His447 ring to form a reactive Glu334- His447-Oxime triad ${ }^{*}, \$$}

Andreas Hörnberg ${ }^{\star \dagger}$, Elisabet Artursson ${ }^{\dagger}$, Rikard Wärme $^{\dagger}$, Yuan-Ping Pang ${ }^{ \pm}$, and Fredrik Ekström ${ }^{\dagger}$

${ }^{\dagger}$ Swedish Defence Research Agency, Division of CBRN Defence and Security, S-901 82, Umeå, Sweden, ${ }^{ \pm}$Computer-Aided Molecular Design Laboratory, Mayo Clinic, Rochester, Minnesota, United States of America.

Corresponding author; Andreas Hörnberg (andreas.hornberg@foi.se)

*This work was supported by the Swedish Armed Forces Research and Technology Program and the Swedish Emergency Management Agency and Swedish Armed Forces Research and Technology Program. Yuan-Ping Pang was supported by the United States Army Medical Research \& Materiel Command (W81XWH-08-1-0154) and the University of Minnesota/Mayo/IBM Collaboration Seed Grant Program.

§The pdb entry codes are XXXX and YYYY for the HI-6•fep-mAChE and Ortho-7•fep-mAChE structures, respectively.

${ }^{1}$ Abbreviations: AChE, acetylcholinesterase; hAChE, Homo sapiens acetylcholinesterase; mAChE, Mus musculus acetylcholinesterase; CAS, catalytic active site; HI-6, [(E)-[1-[(4carbamoylpyridin-1-ium-1-yl)methoxymethyl]pyridin-2-ylidene]methyl]-oxoazanium dichloride; OP, organophosphate; Ortho-7, 1,7-heptylene-bis-N,N'-2-pyridiniumaldoxime dichloride; PAS, peripheral anionic site; sarin, isopropyl methylphosphonofluoridate. The sequence numbering of mAChE is used throughout this paper when amino acids of any AChE are discussed. 
Abstract: Organophosphorus insecticides and nerve agents inhibit the vital enzyme acetylcholinesterase by covalently bonding to the catalytic serine residue of the enzyme. Oxime-based reactivators, such as [(E)-[1-[(4-carbamoylpyridin-1-ium-1yl)methoxymethyl]pyridin-2-ylidene]methyl]-oxoazanium dichloride (HI-6) and 1,7-heptylenebis- $N, N^{\prime}-2$-pyridiniumaldoxime dichloride (Ortho-7), restore the organophosphate-inhibited enzymatic activity by cleaving the phosphorous conjugate. In this article, we report the intermolecular interactions between Mus musculus acetylcholinesterase inhibited by the insecticide fenamiphos (fep-mAChE) and HI-6 or Ortho-7 revealed by a combination of crystallography and reactivation kinetics. The crystal structures of the two oxime-bound fepmAChE complexes show that both oximes interact with the peripheral anionic site involving different conformations of Trp286 and different peripheral-site residues (Tyr124 for HI-6 and Tyr72 for Ortho-7). Moreover, residues at catalytic site of the HI-6-bound fep-mAChE complex adopt conformations that are similar to those in the apo mAChE, whereas significant conformational changes are observed for the corresponding residues in the Ortho-7-bound fep-mAChE complex. Interestingly, flipping of the His447 imidazole ring allows the formation of a hydrogen bonding network among the Glu334-His447-Ortho-7 triad, which presumably deprotonates the Ortho-7 oxime hydroxyl group, increases the nucleophilicity of the oxime group, and leads to cleavage of the phosphorous conjugate. These results offer insights into a detailed reactivation mechanism for the oximes and development of improved reactivators.

Keywords: acetylcholinesterase, X-ray crystallography, activation, histidine-flip, fenamiphos, HI-6, Ortho-7 


\section{Introduction}

The protein acetylcholinesterase (AChE, EC 3.1.1.7) ${ }^{1}$ terminates cholinergic transmission by hydrolysing the neurotransmitter acetylcholine. AChE is a very efficient enzyme and highly susceptible to irreversible inhibition by a class of organophosphates (OPs, e.g., nerve agents and pesticides) which act as a hemi substrate and form a covalent bond to the catalytic Ser2030 $\gamma$. The catalytic site (CAS) of AChE is located close to the bottom of a $\sim 20 \AA$-deep and narrow active-site gorge which accommodates the conjugate through nonbonded interactions at the oxyanion hole (main-chain nitrogen atoms of Gly121, Gly122, and Ala204), the acyl pocket (side chains of the aromatic residues Trp236, Phe295, Phe297 and Phe338) and the choline-binding site (side chains of Trp86 and Tyr337; [1]). At the entrance of the gorge, the peripheral anionic site (PAS; side chains of Tyr72, Asp74, Tyr124, Trp286 and Tyr341) constitutes a binding site for various allosteric modulators and reactivators [2-9]. Even though the interactions of the OP conjugate with AChE are strengthened by a covalent bond, hydrophobic interactions, and hydrogen bonds, spontaneous reactivation (i.e., cleavage of the phosphorus conjugate) as well as elimination (aging) of one of the phosphorous substituents can occur $[10,11]$. The rates $\left(t_{1 / 2}\right)$ of these reactions vary from $\sim 3$ minutes to several days depending upon chemical structures of the phosphorous substituents [12]. Reactivation of the OP-inhibited AChE can be accelerated by nucleophilic substances (i.e. antidotes) which attack the phosphorus atom and cleave the phosphorus conjugate [13]. These antidotes generally contain a pyridiniumaldoxime group as an effective nucleophile (supplementary material online Fig. S1a and S1b); reviewed by [14]). Similar to the spontaneous reactivation or aging reactions, the oxime-mediated reactivation also shows a high variability for different OPs [12].

Previous crystallographic studies showed that carboxyaminopyridinium-containing oximes and bispyridiniumaldoximes form cation-pi interactions with the side chains of Tyr124 and Tyr72, respectively, although they all interact with Trp286, when complexing with nonphosphylated and phosphylated mAChE [7-9]. 
In this study, we present the crystal structures of HI-6 and Ortho-7 in complex with fepmAChE (termed HI-6•fep-mAChE and Ortho-7•fep-mAChE, respectively), and biochemical characterization using a racemic mixture and an optically pure enantiomer of fenamiphos that offers mechanistic interpretations of these structures. We confirm that carboxyaminopyridinium-containing oximes and bis-pyridiniumaldoximeoximes have distinctively different interactions with AChE. Moreover, the His447 imidazole ring flipping leads to the formation of a Glu334-His447-Ortho-7 triad which activates Ortho-7 before transition to the transition state according to our published reactivation mechanism [9].

\section{Materials and Methods}

\section{$\underline{\text { Reactivators and reagents }}$}

Ortho-7 was made according to a published procedure [15]. HI-6 was obtained from Dr. John Clement of Defense Research Establishment, Canada. HEPES (99.5\%), PEG750MME, dichloromethane (99.9\%), 5,5'-dithiobis(2-nitrobenzoic acid) (DTNB, 99\%), acetylthiocholine iodide (ATC, 99\%) and fenamiphos (99.5\%) were obtained from Sigma Aldrich (St. Louis, MO, USA). Sodium chloride (99.5\%), dimethyl sulfoxide (DMSO, 99\%), formic acid $(99 \%)$, sodiumdihydrogenphosphate (99\%) and di-sodiumhydrogenphosphate $(99 \%)$ were purchased from Merck (Darmstadt, Germany). Magnesium sulphate (99\%) and acetonitrile (99.9\%) were obtained from Scharlau Chemie S.A. (Barcelona, Spain). Sodium hydroxide was purchased from Eka Chemicals AB (Bohus, Sweden).

\section{Generation of mAChE and crystallization of its oxime-bound complexes}

Recombinant mAChE protein was cloned, expressed, and purified as previously described [16]. In the crystallization setup, $1 \mu \mathrm{L}$ purified $\mathrm{mAChE}(\sim 20 \mathrm{mg} / \mathrm{mL})$ was mixed with $1 \mu \mathrm{L}$ well solution containing 28\% PEG750MME and 0.1 mM HEPES pH 7.0-7.2. The mAChE crystals were first incubated with aliquots of well solution saturated with fenamiphos $\left(5^{\star} 2 \mu \mathrm{L}\right)$ for 22 
hrs (HI-6•fep-mAChE) and $25 \mathrm{hrs}$ (Ortho-7•fep-mAChE). The $2 \mu \mathrm{L}$ fenamiphos aliquots were added with 1 min intervals. An oxime soaking solution (containing a few grains of $\mathrm{HI}-6$ or Ortho-7) was added to the fenamiphos soaked crystal for 5 and 3 minutes, for HI- 6 and Ortho-7, respectively.

\section{Collection, processing, and refinement of diffraction data}

X-ray diffraction data were collected at the MAXlab synchrotron, beamline 1911-5 (Lund, Sweden) on a MAR research CCD detector. The total oscillation range of the crystals was $180^{\circ}$ and data were collected in $1^{\circ}$ increments. The data were processed using XDS [17] and scaled with SCALA [18]. The structures were solved using rigid body refinement with the mouse apo protein (1J06, [19]) as a starting model. Further refinement was carried out by alternating restrained isotropic B-factor refinement, as implemented in the REFMAC5 program [20], with manual rebuilding of the model after visualization of the $2\left|F_{o}\right|-\left|F_{c}\right|$ and $\left|F_{o}\right|$ - $\left|F_{c}\right|$ maps using the COOT program [21]. The last few rounds of refinement were performed using the Phenix program [22]. The final round of refinement was preceded by addition of both fenamiphos enantiomers into the structure at 0.5 occupancy. To follow the progress of refinement, the $R_{\text {free }}$ value was monitored from the start, with $2 \%$ of the reflections included in the test set [23]. Spartan (Wavefunctions Inc.) was used to calculate the correct bond angles and bond lengths of the fenamiphos-conjugated Ser203. The quality of the final models was evaluated with PROCHECK [24]. Figures were generated using PyMol [25]. Refinement results and the final data collection are summarized in Table 1.

\section{Time-dependent reactivation kinetics of wild type and mutants of $m A C h E$}

Recombinant human AChE (rhAChE) was cloned, expressed, and purified with the same procedure as for the mouse enzyme [16]. Mutants were produced by site-directed mutagenesis as described previously [9]. Purified mAChE wild type $(\sim 200 \mu \mathrm{M})$ was inhibited by $50 \mathrm{mM}$ fenamiphos for $3 \mathrm{hrs}$ to an inhibition grade exceeding $90 \%$ (as a comparison, the aging half-time of fenamiphos is $\sim 140 \mathrm{hrs;}$ [12]). Excess inhibitor was removed by 4 
consecutive desalting columns (Zeba desalt spin column, Pierce Technology) equilibrated in 20 mM HEPES pH 7.0, 50 mM NaCl, 1\% PEG750MME. The inhibited protein was aliquoted, frozen, and stored at $-20^{\circ} \mathrm{C}$ until use. Control AChE was handled simultaneously and with an identical methodology, except that the fenamiphos solution was exchanged for DMSO. The protein was thawed immediately prior to use and the assay was initiated by addition of $\mathrm{HI}-6$ or Ortho-7 at a concentration of 0.1 or $1 \mathrm{mM}$. The reaction was terminated by 4000 -fold and 20000-fold dilutions for the reactions with $100 \mu \mathrm{M}$ and $1 \mathrm{mM}$ reactivator concentration, respectively. The activity was measured by the Ellman assay [26] and the efficiency of the reactivation was calculated as follows:

$$
E=100 \frac{v_{i r} \frac{v_{0}}{v_{r}}-v_{i}}{v_{0}-v_{i}}
$$

Where $E$ represents the percentage of restored enzyme activity, $v_{0}$ the control enzyme activity without inhibitor, $v_{\text {ir }}$ the enzyme activity after reactivation, $v_{i}$ the residual enzyme activity of the inhibited enzyme, and $v_{r}$ is the enzyme activity of the control sample in the presence of a reactivator. The experiments were performed on a Perkin Elmer Lambda18 spectrophotometer.

\section{Separation of enantiomers of fenamiphos and determination of inhibitory potency}

The enantiomers of fenamiphos were separated by using a chiral column (ChromTech Ltd, Cheshire, U.K.). This column, with an i.d. of $150 \times 4.0 \mathrm{~mm}$, has chiral selector alpha1-acid glycoprotein (AGP) coated on spherical $5 \mu \mathrm{m}$ silica particles. The separation was performed using the High Performance Liquid Chromatography (HPLC) system Waters Alliance 2695 Separations Module coupled to a Waters 2996 Photodiode Array Detector (Waters Corporation, Milford, USA).

Racemic fenamiphos (1 $\mathrm{M}$ in DMSO) was diluted to $1 \mathrm{mM}$ in $5 \%$ acetonitrile and injected into the HPLC apparatus using a loop of $20 \mu \mathrm{l}$. Isocratic elution using a mobile phase composed 
of acetonitrile and formic acid $(0.01 \%)$ resulted in near baseline separation of the two enantiomers. To obtain sufficient material for the subsequent experiments, several hundred injections of the racemate were performed. Pooled enantiomer ( $220 \mathrm{ml}$ of each enantiomer) was neutralized by $\mathrm{NaOH}(4 \mathrm{M})$ and $33 \mathrm{ml}$ saturated $\mathrm{NaCl}$ was added prior to extraction of the separated enantiomer in an organic phase of dichloromethane $\left(5^{*} 80 \mathrm{ml}\right)$. The dichloromethane solution containing the optically-pure enantiomer was dehydrated by anhydrous $\mathrm{MgSO}_{4}$ and the filtered solution was concentrated by evaporation to a volume of about $100 \mu \mathrm{l}$. The amount concentrated enantiomer was determined with an internal standard by NMR to $220 \mu \mathrm{g}$ and $129 \mu \mathrm{g}$, for enantiomer-1 (E1) and enantiomer-2 (E2), respectively ( $\mathrm{E} 1$ being the first peak eluted from the chiral column). Exact concentration of dissolved fenamiphos enantiomer in the solution was determined by HPLC using a standard curve with a known concentration of fenamiphos racemate.

Inhibition potency of racemic and $\mathrm{E} 1$ on $\mathrm{mAChE}$ and $h \mathrm{AChE}$ was determined by activity measurements of residual activity. Assuming a pseudo-first-order reaction kinetics, the inhibition constant $\left(k_{i}\right)$ was calculated as follows:

$k_{\mathrm{i}}=\frac{1}{[\mathrm{OP}] t} \ln \frac{v_{\mathrm{o}}}{v_{t}}$

Where $[\mathrm{OP}]$ is the initial concentration of fenamiphos, $v_{0}$ the reaction rate at time zero and $v_{t}$ is the reaction rate at time $t$ [12]. The nonlinear regression curve fit was calculated using the one-phase exponential decay equation as implemented in GraphPad Prism version 3.00 for Windows (GraphPad Software, Inc.).

\section{Results}

General description of the HI-6•fep-mAChE and Ortho-7•fep-mAChE crystal structures

The overall structures of both HI-6•fep-mAChE and Ortho-7•fep-mAChE are similar to the apo structure of mAChE [19]. The initial omit electron density maps show a positive difference electron density, located $\sim 1.6 \AA$ from Ser2030y visible at a contour level of $12 \sigma$ 
(Figs. 1a and b). This electron density accounts for the phosphorous atom of the fenamiphos adduct. The substituents of the fenamiphos are clearly visible in the electron density. Although, features of the electron density maps suggest that the $S$ enantiomer of the fenamiphos phosphorus atom is dominant for HI-6•fep-mAChE at a resolution of $2.7 \AA$ and Ortho-7•fep-mAChE at a resolution $2.4 \AA$, it is not possible to conclusively assign the stereochemistry. Therefore both enantiomers were modelled into the final structure with an occupancy of 0.5 each. This is consistent with inhibition kinetics studies of fenamiphos enantiomers (see below) that show a 3-7 fold difference in potency between the two enantiomers, suggesting that both are present within the crystal structure. Close to 1.0 in occupancy of fenamiphos (i.e., $100 \%$ of the molecules in the crystals are conjugated with fenamiphos) is supported by the fact that no negative electron density (contour level of $3 \sigma$ ) is visible for any atom of the fenamiphos conjugate in a $\left|F_{d}\right|-\left|F_{c}\right|$ electron density map. The electron density map is generally of better quality for monomer A than for monomer $B$ of the asymmetric unit and thereby descriptions of the structures are based on the coordinates from monomer A.

For both complexes, similar to other mAChE structures [7-9, 16, 19, 27-29], the loop region containing residues $258-265$ is disordered and thereby excluded from the models. Residues 490-498 are poorly defined, resulting in unusual backbone torsion angles. For Ortho-7•fepmAChE, residues $493-497$ were omitted at the end of the refinement. The isopropyl- and ethyl substituents of fenamiphos in monomer B of Ortho•fep-mAChE are also excluded in the final structure.

Typically, the C-terminal end is not visible beyond residue 543 in crystal structures of mAChE [7-9, 16, 19, 27-29]. For HI-6•fep-mAChE, a continuous electron density is present at the Cterminal end and defines Ala544, Thr545, and Glu546 in the final model. 


\section{Crystal structure of HI-6•fep-mAChE}

The structure of $\mathrm{HI}-6 \bullet f e p-m A C h E$ was refined at $2.7 \AA$ resolution with an $\mathrm{R}_{\text {factor }}$ of $17\left(\mathrm{R}_{\text {free }}=\right.$ 23) (Table 1). The final structure contains a well defined fenamiphos conjugate as well as most atoms in the HI-6 molecule (Fig. 2a). The two fenamiphos enantiomers have hydrogen bonds between their $-\mathrm{P}=\mathrm{O}$ oxygen atom and the oxyanion hole made of the amide protons of Gly121, Gly122, and Ala204. The corresponding hydrogen bond distances are 2.5 and $2.6 \AA$ (Gly121), 2.5 and $2.5 \AA$ (Gly122), and 3.2 and $3.2 \AA$ (Ala204) for the $S$ and $R$ enantiomers, respectively. One alkyl fenamiphos substituent is accommodated within the acyl pocket. For the $S$ enantiomer, this corresponds to the isopropylamino moiety, whereas the $R$ enantiomer has the ethoxyl moiety in the acyl pocket. The other alkyl fenamiphos substituent is directed towards Trp86 (ethoxyl and isopropylamino substituents for the $S$ and $R$ enantiomer, respectively). The well resolved acyl loop adopts a conformation similar to that in the apo mAChE, which results in short distances to the conjugate. For example, the $\mathrm{C} 2$ atom of isopropylamino moiety for the $S$ isomer is found at distances of $4.0,3.2$, and $3.8 \AA$ to the acyl pocket residues Phe295C $\varepsilon 1$, Phe297C $\zeta$, and Phe338C $\varepsilon 2$, respectively.

Interestingly, the conjugate is tilted towards Trp86 compared to an HI-6 complex with mAChE inhibited by isopropyl methylphosphonofluoridate (sarin) (2WHP; [9] (Fig. 2b), presumably to reduce the clash between the fenamiphos conjugate and the acyl pocket. The tilt of the phosphorous conjugate is primary due to a shift of the main chain of the Ser203-containing loop. Moreover, the torsion angles of the isopropylamino and ethoxyl substituents result in a markedly different conformation of fenamiphos conjugate relative to that of Ortho-7•fepmAChE (see below). The tilt of the phosphorus atom in HI-6•fep-mAChE positions one of the substituents close to Glu202Oع1 and the other substituent close to His447Nع2. For the $S$ enantiomer, the distance between the ethoxy oxygen and Glu2020ع1 atoms is $3.0 \AA$, whereas the isopropylamino nitrogen atom is at a distance of $3.4 \AA$ from the His $447 \mathrm{~N} \varepsilon 2$ 
atom. Conversely, the ethoxy oxygen of the $R$ isomer is positioned at $3.2 \AA$ distance from His447Nع2 and the isopropylamino nitrogen atom is close to Glu202Oع1 (3.2 A).

The binding of HI- 6 to the peripheral site of $m A C h E$ is facilitated by a side chain rotation of Trp286 ( $\sim 90^{\circ}$ rotation about $\chi_{1}$ and a $\sim 100^{\circ}$ rotation about $\left.\chi_{2}\right)$. This structural change allows indole ring of Trp286 and the phenol ring of Tyr124 to sandwich, via cation-pi interactions, by the carboxylamino-pyridinium ring of $\mathrm{HI}-6$. The carboxy oxygen atom of $\mathrm{HI}-6$ is hydrogen bonded to the main-chain nitrogen of Ser298 (2.7 A). Additional interactions between HI-6 and the protein are: an electrostatic interaction between Asp74 and two positive pyridinium rings of $\mathrm{HI}-6$ and cation-pi interactions between the oxime-pyridinium ring and the phenol ring of Tyr341. The interaction between Asp74 and HI-6 positions the $\mathrm{O} \delta 1$ atom at a $3.1 \AA$ distance from the ether oxygen atom. These two atoms are probably engaged in a hydrogen bond network with a water molecule since Asp74 is deprotonated at $\mathrm{pH} 7$. There is a strong electron density feature at a hydrogen bonding distance from the main-chain nitrogen of Phe295 $\left(\mathrm{N}^{\text {Phe295}}\right)$. Modelling the oxime moiety in this density results in a residual positive electron density and poor connectivity between the oxime oxygen atom and the pyridinium ring, similar to a previous report [9]. Attempts to model the oxime moiety (O1, N1 and C1 atoms) were unsuccessful and the oxime moiety was omitted in the final model. Instead, a water molecule accounts for the electron density close to $\mathrm{N}^{\text {Phe295 }}$. Taken together, these observations suggest high mobility of the HI-6 oxime-pyridinium ring, consistent with our reported crystallographic and microsecond molecular dynamics studies of HI-6•sarin ${ }^{\text {nonaged }}$ mAChE [9].

\section{Crystal structure of Ortho-7•fep-mAChE}

The 2.4- $\AA$ resolution crystal structure of Ortho-7•fep-mAChE was refined to a final $R_{\text {factor }}$ of $19\left(R_{\text {free }}=22\right)($ Table 1$)$. Gratifyingly, the final electron density map clearly delineates both 
fenamiphos and Ortho-7 (Fig. 3a) and defines structural changes of the acyl pocket loop (residues 288-299), as well as the side chains of Trp286, Tyr337, Phe338, and His447.

The overall conformation of the fenamiphos conjugate in Ortho-7 is slightly different from that of HI-6•fep-mAChE. For example, the conjugate is not tilted towards Trp86 in Ortho-7•fepmAChE (see below). The ethoxy substituent of the $R$ enantiomer in Ortho-7•fep-mAChE interacts mainly with Trp236 (3.6 A, C5 atom of fenamiphos to Trp236C\&2) and Phe338 (3.5 $\AA$, C5 atom of fenamiphos to Phe $338 \mathrm{C} \zeta$ ) whereas the isopropylamino substituent is directed towards Trp86 ( $5 \AA$ distance, C3 atom of fenamiphos to Trp86C $\varepsilon 3)$. The $S$ enantiomer positions the isopropylamino substituent close to Trp236 and Phe338 and the ethoxy substituent close to Trp86 at similar distances as those in the $R$ enantiomer (Fig. 3b). The interactions of fenamiphos with the oxyanion hole are similar in the Ortho-7- and HI-6containing fep-mAChE complexes; the $-\mathrm{P}=\mathrm{O}$ oxygen atom of the $R$ enantiomer is found 2.9 , 2.6, and $2.9 \AA$ away from the main-chain nitrogen atoms of Gly121, Gly122 and Ala204, respectively $(2.7,2.5$ and 3.3 for the $S$ enantiomer, respectively).

Interestingly, a marked distortion of the acyl pocket loop (residues 288-299) is observed in Ortho-7•fep-mAChE (Fig. 3c). The main-chain movement of the loop is up to $6.0 \AA$ (C $\alpha$ of residue Pro290) relative to that of the apo mAChE. Moreover, two acyl-pocket residues, Phe295 and Phe297, undergo side-chain conformational changes $\left(\sim 78^{\circ}\right.$ and $\sim 137^{\circ}$ for rotation of $\chi_{1}$ for Phe295 and Phe297, respectively) to accommodate a substituent of the fenamiphos conjugate. Consequently, the conjugate in Ortho-7•fep-mAChE is not tilted towards Trp86, and slightly different torsion angles of the fenamiphos conjugate result in a more extended conformation of the fenamiphos substituents than that in HI-6•fep-mAChE.

Similar to our previous crystal structures of Ortho-7, one of the oxime-pyridinium rings is sandwiched between Trp286 and Tyr72 with the oxime oxygen hydrogen bonding to 
Glu2850ع1 (2.5 $\AA$ ). To form the sandwich, the side chain of Trp286 rotates $\sim 90^{\circ}$ about $\chi_{1}$ and $\sim 150^{\circ}$ about $\chi_{2}$. The other oxime pyridinium of Ortho-7 is close to the fenamiphos adduct (3.5 $\AA$ to the isopropylamino substituent of the $R$ enantiomer and $3.6 \AA$ to the $S$ enantiomer) and positioned nearly parallel to Tyr337 (Fig. 3d). The structural change of the acyl loop results in hydrophobic interactions between the heptylene linker of Ortho-7 and Leu294. Interestingly, the oxime oxygen atom at the catalytic site forms a hydrogen bond to His447Nع2 (2.8 $\AA$ ), positioning the nucleophilic oxime oxygen atom 5.7-5.9 $\AA$ away from the phosphorus atom. This hydrogen bond is possible due to a side chain rotation of His447 (an imidazole ring flip: $\sim 140^{\circ}$ about $\chi_{1}$ and $\sim 180^{\circ}$ about $\left.\chi_{2}\right)$ and Tyr337 $\left(\sim 30^{\circ}\right.$ about $\chi_{1}$ and $\sim 60^{\circ}$ about $\left.\chi_{2}\right)$ as well as retraction of Phe338 (3.0 $\AA$ for the $\mathrm{C} \zeta$ atom relative to that of the apo mAChE structure) (Fig. 3d). A residual and positive electron density feature was observed near His447, which probably represents a low-occupancy conformation of His447 found in the apo mAChE structure. However, the apo-like conformation is estimated to have an occupancy below $10 \%$ and is therefore not included in the final structure. In addition, two residual and positive electron density features close to the fenamiphos conjugate could not be unambiguously identified (supplementary material online Fig. S2). These electron density features are visible at $4.5 \sigma$ in the final $\left|F_{o}\right|-\left|F_{c}\right|$ electron density map and positioned $3.0 \AA$ away from the C2 and the C5 atoms of the fenamiphos conjugate. These features may represent low-occupancy water molecules and suggest that a fraction of the conjugate is aged (note that no residual negative electron density is observed for the phosphorus atom). Nevertheless, the non-aged fenamiphos adduct to Ser203 is the dominating species with $>90$ $\%$ occupancy.

\section{Biochemical characterization}

To assign the stereochemistry of the phosphorous conjugate in HI-6•fep-mAChE and Ortho7•fep-mAChE, a biochemical characterization study using an optically pure fenamiphos enantiomer was performed. The enantiomer was obtained by isocratic elution using a chiral 
column, resulting in an optical purity of $>98 \%$ and $\sim 96 \%$, for enantiomer-1 (E1) and enantiomer-2 (E2), respectively (supplementary material online Fig. S3). The bimolecular rate constant for the inhibition $\left(k_{\mathrm{i}}\right)$ of $r$ AChE was higher for $\mathrm{E} 1$ than for racemic fenamiphos $\left(16.8 \pm 0.8 \times 10^{3}\right.$ vs. $\left.5.5 \pm 0.7 \times 10^{3} \mathrm{M}^{-1} \mathrm{~min}^{-1}\right)$ and a comparable result was obtained for $\mathrm{mAChE}$ $\left(3.0 \pm 0.6 \times 10^{3}\right.$ vs. $\left.1.0 \pm 0.1 \times 10^{3} \mathrm{M}^{-1} \mathrm{~min}^{-1}\right)$. Since $\mathrm{E} 2$ contained $\sim 4 \%$ of $\mathrm{E} 1$, the bimolecular rate constant of E2 was not determined. However, by testing the inhibition of hAChE by E1 and E2 at nearly equimolar concentrations, E1 is estimated to be $3-7$ fold more potent than E2 (supplementary material online Fig. S4).

The short distances between the fenamiphos conjugate and the side chains of Phe295 and Phe297, which presumably cause the tilt of the conjugate observed in HI-6•fep-mAChE, lead us to investigate the inhibition of Phe295Ala and Phe297Ala mutants of hAChE by fenamiphos. The human enzyme was used to compare with a previous report [30] and due to similar reactivation kinetics of human and rat AChEs [31], high similarity among human, rat and mouse AChEs ( $89 \%$ sequence identity between the human and rat enzymes; $98 \%$ sequence identity between the rat and mouse enzymes), and the same active-site residues in the three enzymes. Compared to wild type, the inhibitions of Phe295Ala and Phe297Ala by E1 increased by $\sim 3$ fold $\left(k_{\mathrm{i}}=45.2 \pm 1.1 \times 10^{3} \mathrm{M}^{-1} \mathrm{~min}^{-1}\right)$ and decreased by $\sim 5$ fold $\left(k_{\mathrm{i}}=3.5 \pm\right.$ $\left.0.2 \times 10^{3} \mathrm{M}^{-1} \mathrm{~min}^{-1}\right)$, respectively. Moreover, a comparison of the enantiomers at nearly equimolar concentrations shows that E1 is more potent than E2 for both mutants (Fig. S4). Thus, the stereochemical preference is independent upon the residue substitutions in the acyl pocket.

To compare the efficacies of $\mathrm{HI}-6$ and Ortho-7 in reactivating the fenamiphos-inhibited mAChE at the same $\mathrm{pH}$ as used during the crystal soaking, mAChE was inhibited by fenamiphos and the amount of reactivation was then measured after 1- and 3-hour incubations with HI-6 or Ortho-7. At an oxime concentration of $1 \mathrm{mM}, \mathrm{HI}-6$ has a higher 
efficacy than Ortho-7 ( $27.3 \pm 3.4 \%$ vs. $14.7 \pm 0.4 \%$ restored activity after $3 \mathrm{hrs})$ (Table 2$)$. On the other hand, at a lower oxime concentration $(0.1 \mathrm{mM})$, their efficacy on fep-mAChE is similar (11.6 $\pm 1.7 \%$ and $11.1 \pm 0.7 \%$ for Ortho- 7 and $\mathrm{HI}-6$, respectively).

\section{Discussion}

Structural Requirement for the Reactivation of fep-mAChE

We recently proposed a mechanism for the reactivation of sarin ${ }^{\text {nonaged }}-\mathrm{mAChE}$ by $\mathrm{HI}-6$ in which a reactive tetrad (Glu334-His447-Water-HI-6) is formed to deprotonate the hydroxyl group of $\mathrm{HI}-6$ in the HI-6•sarin ${ }^{\text {nonaged }}$-mAChE complex at the Michaelis-Menten state [9]. In the mechanism, His447 plays a key role in reactivation since the imidazole ring not only activates the oxime oxygen atom by accepting the hydroxyl proton, but also donates a proton to Ser2030 $\gamma$ at the transition state. In this context, the structure of Ortho-7•fep-mAChE is of particular interest since a significant structural change of His447 is clearly defined by the electron density map. Indeed, the Ortho-7•fep-mAChE crystal structure shows an analogous hydrogen bond network among Glu334, His447 and the oxime oxygen of Ortho-7 (supplementary material Fig. S5a). Interestingly, flipping the His447 imidazole ring relative to the apo mAChE is necessary to establish a reactive triad of Glu334-His447-Ortho-7. The flipstate of imidazole rings are sometimes difficult to deduce because of similar electron densities of nitrogen and carbon [32]. Moreover, in Ortho-7•fep-mAChE, both the flipped and unflipped imidazole ring conformations result in short C-to-C distances. However, analysis of the hydrogen bonding distances and angles for the two conformations indicates that the unflipped imidazole ring conformation is less favourable (supplementary material Fig. S5b). It is conceivable that the Glu334-His447-Ortho-7 triad increases the nucleophilicity of the oxime just as the Glu334-His447-Water-HI-6 tetrad [9]. In excellent agreement with this finding, the imidazole ring flip that permits the formation of the Glu334-His447-Ortho-7 triad is also present in our previously reported structure of tabun-inhibited $m A C h E$ in complex with Ortho-7 [8]. An imidazole ring flip has also been reported to produce a catalytic triad in 
glycinamide ribonucleotide transformylase (GART), where the formation of the Asp144His108-GAR (glycinamide ribonucleotide) triad deprotonates the GAR molecule [33].

In contrast to the conformational change of His447 in Ortho-7•fep-mAChE as described above, His447 adopts the conformation found the in the apo mAChE structure and no imidazole ring flip is observed in HI-6•fep-mAChE. Despite extensive model-building trials, the oxime moiety of HI-6 could not be modelled into the HI-6•fep-mAChE structure. One plausible explanation for the missing of electron density for the oxime moiety is that the oxime-pyridinium ring of $\mathrm{HI}-6$ is mobile, consistent with our recently reported crystallography and microsecond multiple molecular dynamics simulations (MMDSs) of $\mathrm{HI}-6 \bullet s^{2}$ rin $^{\text {nonaged }}$ mAChE [9]. Since the oxime moiety is undetermined, microsecond MMDSs are necessary to confirm the mobility and investigate deprotonation of $\mathrm{HI}-6$ by a putative tetrad or triad in the fenamiphos-containing active site.

Relative Reactivation Potencies of HI-6 and Ortho-7

Our biochemical characterization shows that that $\mathrm{HI}-6$ is a more efficient reactivator than Ortho-7 at $1 \mathrm{mM}$, whereas the efficacies of the two oximes are similar at $100 \mu \mathrm{M}$ (Table 2). At $1 \mathrm{mM}$, the concentration is likely above the dissociation constant $\left(K_{D}\right)$ for both HI-6 and Ortho-7 ( $K_{\mathrm{D}}$ for $\mathrm{HI}-6$ of fenamiphos-bound $h \mathrm{AChE}$ is $889 \mu \mathrm{M}$ [12]). For $\mathrm{HI}-6$, the reactivation is reduced by 2 fold at lower oxime concentration, while for Ortho- 7 the effect of the decreased concentration on efficacy is insignificant, suggesting that $K_{\mathrm{D}}$ for Ortho-7 is below $100 \mu \mathrm{M}$. Under the assumptions that the stereochemical preferences for fenamiphos by HI-6 and Ortho-7 are similar and that the stabilities of the phosphorylated oximes of HI-6 and Ortho-7 are also comparable, these reactivation results along with the structural consideration discussed below suggest that Ortho-7 has a higher affinity than $\mathrm{HI}-6$ for fepmAChE, whereas HI-6 has a higher reactivation rate than Ortho-7. 
Structural Basis for the Higher Reactivation Rate of HI-6 than Ortho-7

The tilted conjugate in HI-6•fep-mAChE pushes one of the fenamiphos substituents towards the $\mathrm{HI}-6$ binding site, resulting in a translation of the oxime-pyridinium ring of $\mathrm{HI}-6$ towards Trp286. Superposition of the available HI-6-containing mAChE structures shows that the position of fenamiphos in HI-6•fep-mAChE creates incompatibly short C-to-C distances between fenamiphos and the site favoured by HI-6 in non-conjugated mAChE and $\mathrm{HI}-$ $6 \bullet$ sarin-mAChE $[7,9]$. In contrast to the disordered electron density of the oxime-pyridinium of $\mathrm{HI}-6$, the well resolved electron density map of Ortho-7•fep-mAChE shows extensive and favourable interactions between Ortho- 7 and fep-mAChE, including the hydrogen bond to His447 described above. These observations support the notion that Ortho-7 has a higher affinity than HI-6 for fep-mAChE.

Because of the higher affinity of Ortho-7 for fep-mAChE, one can speculate that the hydrogen bond between His447 and the oxime oxygen of Ortho-7 entraps the nucleophile at the Michaelis-Menten state and hampers the conversion to the transition state. Moreover, the His447Nع2 atom is $5.4-5.5 \AA$ away from Ser2030 $\gamma$, which indicates that a conformation change of His447 is necessary to donate a proton to Ser2030 $\gamma$ at the transition state [9]. Taken together, it is conceivable that the higher reactivation rate of $\mathrm{HI}-6$ than Ortho-7 in reactivating fenamiphos-AChE is due to a mobile oxime-pyridinium and the apo-like conformation of His447, two factors that facilitate the conversion from the Michaelis-Menten state to the transition state as well as the protonation of Ser2030 $\gamma$ at the transition state.

Allosteric modulation of the acyl pocket

Superposition of the HI-6•fep-mAChE and Ortho-7•fep-mAChE structures shows that the phosphorous conjugate in the HI-6-containing complex is tilted toward Trp86 (Fig. 3b). The $1.2-\AA$ tilt of the phosphorus atom, in combination with strained torsion angles of the fenamiphos conjugate in HI-6•fep-mAChE, allows an apo-like conformation of the acyl loop. 
In contrast, a striking feature of Ortho-7•fep-mAChE is the extensive structural change of the acyl loop (Fig. 3c). The distortion of the acyl loop may be explained by steric effects induced by the Ortho-7 pyridinium ring positioned in the catalytic site nearly parallel to Tyr337. In this position, the pyridinium ring of Ortho-7 is incompatible, due to short C-to-C distances, with the tilted fenamiphos conjugate conformation observed in HI-6•fep-mAChE. Thus, one of the fenamiphos substituents is shifted towards the acyl loop, presumably inducing the structural change of the loop. The new position of acyl loop provides space to accommodate the fenamiphos substituent and, consequently, no tilt of the phosphorus conjugate is present in Ortho-7•fep-mAChE. A tilted conjugated serine residue has previously been described for aged phosphoroamidates in butyrylcholinesterase. The tilt is due to a salt bridge between the negative charged dealkylated aging product and the histidine corresponding to His447 in AChE (His438 in butyrylcholinesterase) [34].

It has been suggested that an ethoxy group may fit the acyl pocket without perturbing the conformations of Phe295 and Phe297 found in the apo mAChE structure [30]. This proposal was based on two observations of conjugates with one methyl- and one ethoxy substituent; i) inhibition kinetics where an increased size of the acyl pocket (Phe295Ala) had a small effect ( 1.5 fold) on the reactivity for the $R$ stereoisomer of non-charged O-ethyl S-3-(isopropyl-4methylpentyl) methylphosphonothioate $(P[R] \mathrm{ncVX})$ which has the ethoxy moiety towards the acyl pocket [30] and ii) the lack of stereoselectivity for MEPQ (7(methylethoxyphosphinyloxy)1-methyl-quinolinium iodide), which has a methyl- and an ethoxy substituent [35]. In the present study, inhibitions of wild type hAChE, Phe295Ala and Phe297Ala by separated fenamiphos enantiomers show that none of the two mutants reverses the stereochemical preference. Moreover, for the more reactive enantiomer, the Phe295Ala mutation increases the inhibition constant by $\sim 3$ fold whereas the Phe297Ala mutation decreases the inhibition by $\sim 5$ fold. Thus, in this respect, our findings are consistent with the reported kinetics of methylphosphonates $\mathrm{P}[R] \mathrm{ncVX}$ and MEPQ (i.e., one of the 
fenamiphos substituents can be accommodated in the acyl pocket without inducing a structural change).

On the other hand, inhibition kinetics of the phosphates ethylparaoxon, diethylfluorophosphate (DEFP) and echothiophate show a 20-40 fold enhanced inhibition potency in the Phe295Ala mutant $[30,36]$. One obvious difference between the methyl phosphonates discussed above and these phosphates is that the methyl phosphonates have methyl and ethoxy substituents whereas the phosphates have two ethoxy substituents. As previously reported, this indicates that interactions between two fenamiphos substituents that are distal from the acyl loop affect the accommodation of the phosphorus conjugate [33].

\section{Difference between Ortho-7•tabun-mAChE and Ortho-7•fep-mAChE}

In the previously reported Ortho-7•tabun-mAChE structure (2JF0; [8]), the triad (Glu334His447-Ortho-7) is also observed. The His447 residue is in a similar position and has a flipped imidazole ring just as described in Ortho-7•fep-mAChE. However, in the tabunconjugated structure, the distance between His447 and the oxime oxygen of Ortho-7 is significantly longer than the distance in the fenamiphos-conjugated structure (supplementary material online Fig. S6). The structural change of the acyl loop in Ortho-7•fep-mAChE allow a 2-3 $\AA$ adaptive structural change of Phe338, which in turn permits the stronger interaction between the oxime oxygen and His447. Another difference between the fenamiphos- and tabun-containing structures is that in Ortho-7 -tabun-mAChE, the electron density map of the oxime-pyridinium is relatively weak and shows notably short interaction distances to Tyr337 and Phe338 implying that the oxime-pyridinium is mobile in the tabun-containing complex.

Flexibility of the acyl loop

A superposition of three available complexes of Ortho-7-bound mAChE (Ortho-7 in complex with $m A C h E$, tabun-mAChE and fep-mAChE) shows a similar interaction between AChE and 
the pyridinium ring at the catalytic site, whereas the pyridinium ring at the peripheral site and the central linker is markedly different in the fenamiphos-inhibited complex (Fig. 4). The different binding of the Ortho-7 linker in the fenamiphos-inhibited complex is due to the structural change of the acyl loop, which pushes the side chain of Ile294 into the active-site gorge where it forms hydrophobic interactions with the linker of Ortho-7. An adaptable central linker is consistent with the previous suggestion that Ortho-7 can adjust to different conformations of the active-site gorge [7]. Moreover, the acyl loop has previously been described as flexible and various reversible and irreversible ligands are known to induce a structural change in this region [29, 37-39]. For example, side-chain rotations of Phe295 and Phe297, similar to the movement observed in Ortho-7•fep-mAChE, have been described in the bis-tacrine-bound Torpedo californica AChE complex (pdb code: 2cmf; [39]).

Effect of conjugation on the acyl loop conformation

Analogously, nonaged and aged forms of diisopropyl fluorophosphate (DFP) and the aged form of fenamiphos induce structural changes of the acyl loop upon conjugating to Ser203 $[29,37]$. The acyl loop of the previously reported nonaged form of fep-mAChE adopts a conformation found in the apo mAChE structure; however, due to the low occupancy of the phosphorous conjugate in fep-mAChE, the reported stereochemistry as well as the position of the acyl loop [29] need further confirmation. Despite the apo-like conformation acyl loop in $\mathrm{HI}-6 \cdot \mathrm{fep}-\mathrm{mAChE}$, it is likely that aging of fenamiphos occur via the same mechanism as described for tabun, i.e., His447 is involved as a catalyst for aging and subsequently stabilizes the negatively charged dealkylated product [40].

\section{Conclusion}

The data presented herein propose that an imidazole ring flip of His447 is required to establish a favourable hydrogen bond network among a triad (Glu334-His447-Oxime) that can increase the nucleophilicity of the Ortho-7 oxime due to deprotonation of the oxime group by the triad but can also reduce the reactivation potency due to entrapment of Ortho-7 
at the Michaelis-Menten state by the triad. For our ongoing structure-based design of novel nerve-agent antidotes, these findings highlight an array of complex relations between the catalytic-site architecture and the spatial arrangements of the phosphorus conjugate and the attacking oxime. We suggest that novel reactivators should be designed in such a way that His447 can participate in a transient Glu334-His447-(Wat)-Oxime arrangement. 


\section{Acknowledgements}

We thank Drs. Tomas Ursby and Krister Larsson for assistance at the beamline 1911 at the

MAXlab synchrotron, Lund, Sweden.

\section{References}

[1] Harel M, Quinn DM, Haridasan KN, Silman I, Sussman JL. The X-ray Structure of a Transition State Analogue Complex Reveals the Molecular Origins of the Catalytic Power and Substrate Specificity of Acetylcholinesterase. J Am Chem Soc 1996;118:2340-6.

[2] Radic Z, Reiner E, Taylor P. Role of the peripheral anionic site on acetylcholinesterase: inhibition by substrates and coumarin derivatives. Mol Pharmacol 1991;39:98-104.

[3] Shafferman A, Velan B, Ordentlich A, Kronman C, Grosfeld H, Leitner M, et al. Substrate inhibition of acetylcholinesterase: residues affecting signal transduction from the surface to the catalytic center. Embo J 1992;11:3561-8.

[4] Barak D, Kronman C, Ordentlich A, Ariel N, Bromberg A, Marcus D, et al. Acetylcholinesterase peripheral anionic site degeneracy conferred by amino acid arrays sharing a common core. J Biol Chem 1994;269:6296-305.

[5] Eichler J, Anselment A, Sussman JL, Massoulie J, Silman I. Differential effects of "peripheral" site ligands on Torpedo and chicken acetylcholinesterase. Mol Pharmacol 1994;45:335-40.

[6] Rosenberry TL, Mallender WD, Thomas PJ, Szegletes T. A steric blockade model for inhibition of acetylcholinesterase by peripheral site ligands and substrate. Chem Biol Interact 1999;119-120:85-97.

[7] Ekström F, Pang YP, Boman M, Artursson E, Börjegren S. Crystal structures of acetylcholinesterase in complex with HI-6, Ortho-7 and obidoxime: Structural basis for differences in the ability to reactivate tabun conjugates. Biochemical Pharmacology 2006;72:597-607.

[8] Ekstrom FJ, Astot C, Pang YP. Novel nerve-agent antidote design based on crystallographic and mass spectrometric analyses of tabun-conjugated acetylcholinesterase in complex with antidotes. Clin Pharmacol Ther 2007;82:282-93.

[9] Ekstrom F, Hörnberg A, Artursson E, Hammarström LG, Schneider G, Pang YP. Structure of HI-6•Sarin-Acetylcholinesterase Determined by X-ray Crystallography and Molecular Dynamics Simulation: Reactivator Mechanism and Design. PLoS ONE 2009;4:e5957.

[10] Benschop HP, Keijer JH. On the mechanism of aging of phosphonylated cholinesterases. Biochim Biophys Acta 1966;128:586-8.

[11] Michel HO, Hackley BE, Jr., Berkowitz L, List G, Hackley EB, Gillilan W, et al. Ageing and dealkylation of Soman (pinacolylmethylphosphonofluoridate)-inactivated eel cholinesterase. Arch Biochem Biophys 1967;121:29-34.

[12] Worek F, Thiermann H, Szinicz L, Eyer P. Kinetic analysis of interactions between human acetylcholinesterase, structurally different organophosphorus compounds and oximes. Biochem Pharmacol 2004;68:2237-48.

[13] Hobbiger $F$. The inhibition of acetylcholinesterase by organophosphorus compounds and its reversal. Proc R Soc Med 1961;54:403-5.

[14] Kuca K, Jun D, Musilek K, Bajgar J. Reactivators of Tabun-Inhibited Acetylcholinesterase: Structure-Biological Activity Relationship. Frontiers in Drug Design Discovery 2007;3:381-94.

[15] Pang YP, Kollmeyer TM, Hong F, Lee JC, Hammond PI, Haugabouk SP, et al. Rational design of alkylene-linked bis-pyridiniumaldoximes as improved acetylcholinesterase reactivators. Chem Biol 2003;10:491-502.

[16] Ekström F, Akfur C, Tunemalm A-K, Lundberg S. Structural changes of phenylalanine 338 and histidine 447 revealed by the crystal structures of tabun-inhibited murine acetylcholinesterase. Biochemistry 2006;45:74-81.

[17] Kabsch W. Automatic processing of rotation diffraction data from crystals of initially unknown symmetry and cell constants. J Appl Cryst 1993;26:795-800.

[18] Kabsch W. Evaluation of single-crystal X-ray diffraction data from a position-sensitive detector. J Appl Cryst 1988;21:916-24. 
[19] Bourne $Y$, Taylor $P$, Radic $Z$, Marchot $P$. Structural insights into ligand interactions at the acetylcholinesterase peripheral anionic site. Embo J 2003;22:1-12.

[20] Murshudov GN, Vagin AA, Dodson EJ. Refinement of Macromolecular Structures by the Maximum-Likelihood Method. Acta Crystallogr D Biol Crystallogr 1997;D53:240-55.

[21] Emsley P, K C. Coot: model-building tools for molecular graphics. 2004.

[22] Adams PD, Grosse-Kunstleve RW, Hung LW, loerger TR, McCoy AJ, Moriarty NW, et al. PHENIX: building new software for automated crystallographic structure determination. Acta Crystallogr D Biol Crystallogr 2002;58:1948-54.

[23] Brunger AT. Free $R$ value: a novel statistical quantity for assessing the accuracy of crystal structures. Nature 1992;355:472-4.

[24] Laskowski RA, MacArthur MW, Moss DS, Thornton JM. PROCHECK: a program to check the stereochemical quality of protein structures. J Appl Cryst 1993;26:283-91.

[25] DeLano WL. The PyMOL Molecular Graphics System. 2002.

[26] Ellman GL, Courtney KD, Andres V, Jr., Feather-Stone RM. A new and rapid colorimetric determination of acetylcholinesterase activity. Biochem Pharmacol 1961;7:88-95.

[27] Bourne Y, Kolb HC, Radic Z, Sharpless KB, Taylor P, Marchot P. Freeze-frame inhibitor captures acetylcholinesterase in a unique conformation. Proc Natl Acad Sci U S A 2004;101:1449-54.

[28] Bourne Y, Radic Z, Sulzenbacher G, Kim E, Taylor P, Marchot P. Substrate and product trafficking through the active center gorge of acetylcholinesterase analyzed by crystallography and equilibrium binding. J Biol Chem 2006.

[29] Hornberg A, Tunemalm AK, Ekstrom F. Crystal Structures of Acetylcholinesterase in Complex with Organophosphorus Compounds Suggest that the Acyl Pocket Modulates the Aging Reaction by Precluding the Formation of the Trigonal Bipyramidal Transition State. Biochemistry 2007;46:4815-25.

[30] Ordentlich A, Barak D, Sod-Moriah G, Kaplan D, Mizrahi D, Segall Y, et al. Stereoselectivity toward VX is determined by interactions with residues of the acyl pocket as well as of the peripheral anionic site of AChE. Biochemistry 2004;43:11255-65.

[31] Worek F, Reiter G, Eyer, P, Szinicz L. Reactivation kinetics of acetylcholinesterase from different species inhibited by highly toxic organophosphates. Arch Toxicol. 2002;76:523-9.

[32] Nielsen JE, Andersen KV, Honig B, Hooft RWW, Klebe G, Vriend G, et al. Improving macromolecular electrostatics calculations. Protein Eng 1999;12:657-62.

[33] Morikis D, Elcock AH, Jennings PA, McCammon JA. Proton transfer dynamics of GART: The pH-dependent catalytic mechanism examined by electrostatic calculations. 2001.

[34] Carletti E, Aurbek N, Gillon E, Loiodice M, Nicolet Y, Fontecilla-Camps JC, et al. Structureactivity analysis of aging and reactivation of human butyrylcholinesterase inhibited by analogues of tabun. Biochem J 2009;421:97-106.

[35] Levy D, Ashani $Y$. Synthesis and in vitro properties of a powerful quaternary methylphosphonate inhibitor of acetylcholinesterase. A new marker in blood-brain barrier research. Biochem Pharmacol 1986;35:1079-85.

[36] Ordentlich A, Barak D, Kronman C, Ariel N, Segall Y, Velan B, et al. The architecture of human acetylcholinesterase active center probed by interactions with selected organophosphate inhibitors. J Biol Chem 1996;271:11953-62.

[37] Millard CB, Kryger G, Ordentlich A, Greenblatt HM, Harel M, Raves ML, et al. Crystal structures of aged phosphonylated acetylcholinesterase: nerve agent reaction products at the atomic level. Biochemistry 1999;38:7032-9.

[38] Greenblatt HM, Guillou C, Guénard D, Argaman A, Botti S, Badet B, et al. The Complex of a Bivalent Derivative of Galanthamine with Torpedo Acetylcholinesterase Displays Drastic Deformation of the Active-Site Gorge: Implications for Structure-Based Drug Design. J Am Chem Soc 2004;126:15405-11.

[39] Rydberg EH, Brumshtein B, Greenblatt HM, Wong DM, Shaya D, Williams LD, et al. Complexes of alkylene-linked tacrine dimers with Torpedo californica acetylcholinesterase: Binding of Bis5-tacrine produces a dramatic rearrangement in the active-site gorge. J Med Chem 2006;49:5491-500.

[40] Carletti E, Li H, Li B, Ekstrom F, Nicolet Y, Loiodice M, et al. Aging of cholinesterases phosphylated by tabun proceeds through O-dealkylation. J Am Chem Soc 2008;130:1601120. 


\section{Figure legends}

Fig. 1. Electron density maps of HI-6•fep-mAChE (A) and Ortho-7•fep-mAChE (B) calculated after simulated annealing using models where the conjugated Ser203 and oximes were omitted. The $\left|F_{o}\right|-\left|F_{c}\right|$ electron density maps are contoured at $3 \sigma$ (blue) and $12 \sigma$ (red).

Fig. 2. (A) The fenamiphos conjugate and the HI-6 molecule of HI-6•fep-mAChE covered by the electron density at $1 \sigma$ in a $2\left|F_{o}\right|-\left|F_{c}\right|$ map. (B) The conjugate of HI-6•fep-mAChE (lime) is tilted towards Trp86 compared to the conjugate of HI-6•sarin-mAChE (brown).

Fig. 3. (A) The fenamiphos conjugate and the Ortho-7 molecule of Ortho-7•fep-mAChE covered by the electron density at $1 \sigma$ in a $2\left|F_{o}\right|-\left|F_{c}\right|$ map. (B) The fenamiphos substituents (isopropylamino- and ethoxy group) in Ortho-7•fep-mAChE (cyan) compared to the corresponding atoms in HI-6•fep-mAChE (lime). (C) Disruption of the acyl pocket in Ortho7•fep-mAChE (cyan), where both the acyl loop (containing Phe295 and Phe297) and Phe338 has moved compared to the apo protein (grey). Residues Tyr337 and His447 have been omitted for clarity. (D) The position of the attacking pyridinium ring of Ortho-7•fep-mAChE compared to the corresponding pyridinium ring in HI-6•fep-mAChE. The figure is in similar view as in (C).

Fig. 4. A superposition of Ortho-7•fep-mAChE (cyan) onto Ortho-7•mAChE (pink), and Ortho-7•tabun-mAChE (violet) shows different binding of the central linker in the fenamiphos inhibited complex. The black dashed lines indicates close $\mathrm{C} \cdots \mathrm{C}$ contacts. 
Supplementary material:

Fig. S1. The chemical structure of the oxime based reactivators (A) Ortho-7, (B) HI-6; the OP compounds $(\mathrm{C})$ fenamiphos.

Fig. S2. Positive electron density features close to the fenamiphos conjugate at $4.5 \sigma$ in the final $\left|F_{o}\right|-\left|F_{c}\right|$ electron density map.

Fig. S3. Separation of enantiomers of fenamiphos; (A) the racemic solution, (B) E1 and (C) E2.

Fig. S4. Inhibition of E1 ( $\mathbf{a})$ and E2 ( $\mathbf{\Delta})$ on hAChE for wild type (A), F295A (B), and F297A (C). E1 concentration inhibiting wild type is $17.6 \mu \mathrm{M}$ (E2 concentration is $18.9 \mu \mathrm{M})$. For Phe295Ala and Phe297Ala the concentrations are $10 \mu \mathrm{M}$ and $80 \mu \mathrm{M}$ for both enantiomers, respectively.

Fig. S5. (A) An simulated annealing omit $\left|F_{o}\right|-\left|F_{c}\right|$ electron density map of the Glu334His447-Ortho-7 triad contoured at $3 \sigma$, where the triad residues were excluded from the map calculation. (B) The alternative histidine-flip is not likely due to a less favourable hydrogen bonding network. The red dashed line indicates possible hydrogen bonds and black dashed lines indicates close $\mathrm{N} \cdots \mathrm{C}$ contacts.

Fig. S6. The attacking pyridinium ring of Ortho-7 in Ortho-7 •fep-mAChE (cyan) compared to Ortho-7 -tabun-mAChE (violet). The red dashed line indicates a strong hydrogen bond and a green dashed line indicates a weak hydrogen bond (3.3 $\AA$ ). 
Table 1. Data collection and refinement statistics of the complexes.

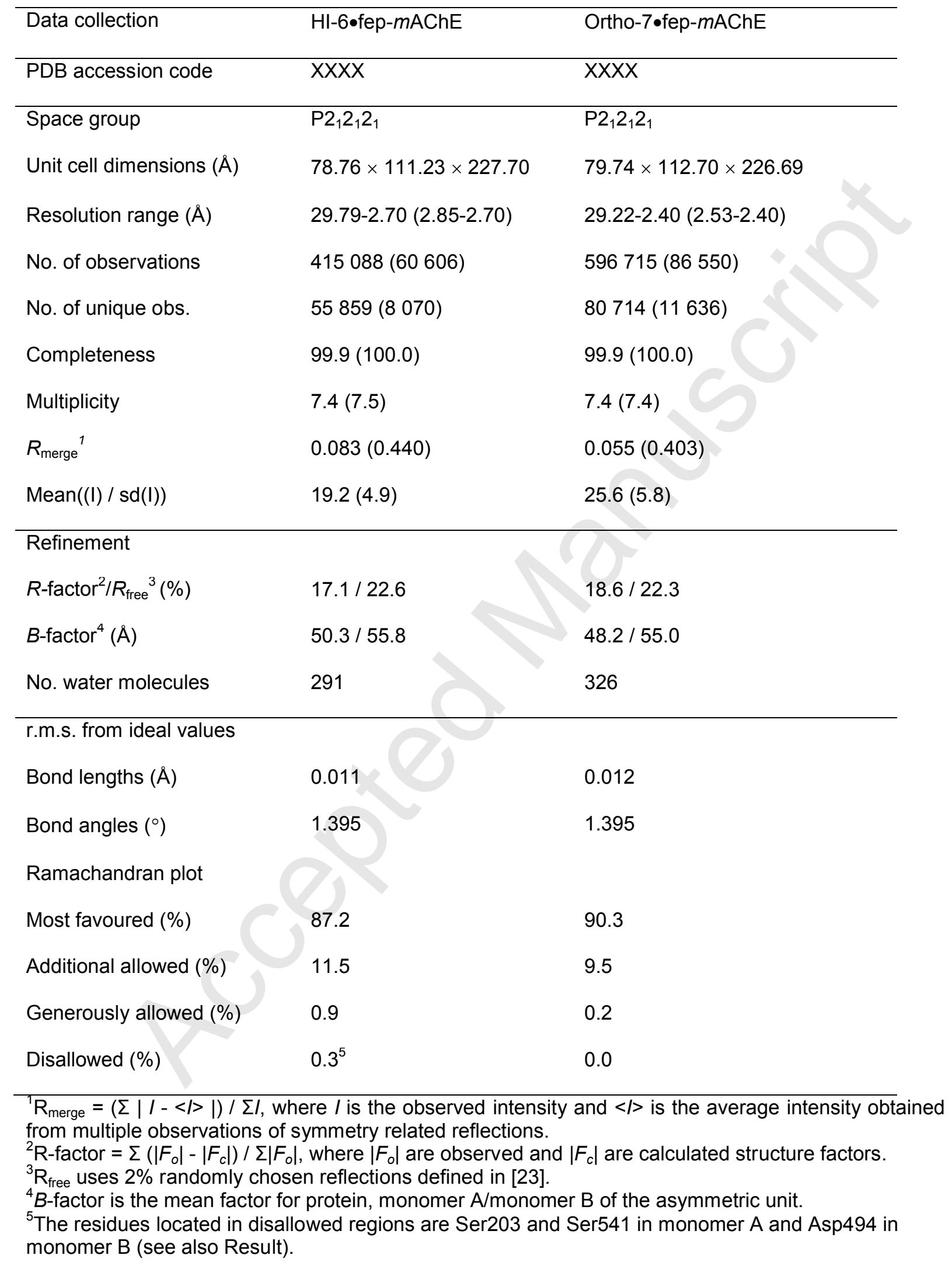


Table 2. Time dependent reactivation of fenamiphos-inhibited mAChE in conditions simulating the crystallization setup.

\begin{tabular}{|c|c|c|}
\hline & $\begin{array}{c}\mathrm{HI}-6 \\
\text { (\% reactivated })\end{array}$ & $\begin{array}{c}\text { Ortho-7 } \\
\text { (\% reactivated })\end{array}$ \\
\hline $100 \mu \mathrm{M}, 1 \mathrm{hr}$ & $4.5 \pm 1.2$ & $5.8 \pm 1.1$ \\
\hline $100 \mu \mathrm{M}, 3 \mathrm{hr}$ & $11.1 \pm 0.7$ & $11.6 \pm 1.7$ \\
\hline \multicolumn{2}{|l}{} \\
\hline $1 \mathrm{mM}, 1 \mathrm{hr}$ & $10.3 \pm 2.6$ & $5.7 \pm 3.0$ \\
\hline $1 \mathrm{mM}, 3 \mathrm{hr}$ & $27.3 \pm 3.4$ & $14.7 \pm 0.4$ \\
\hline
\end{tabular}


(A)
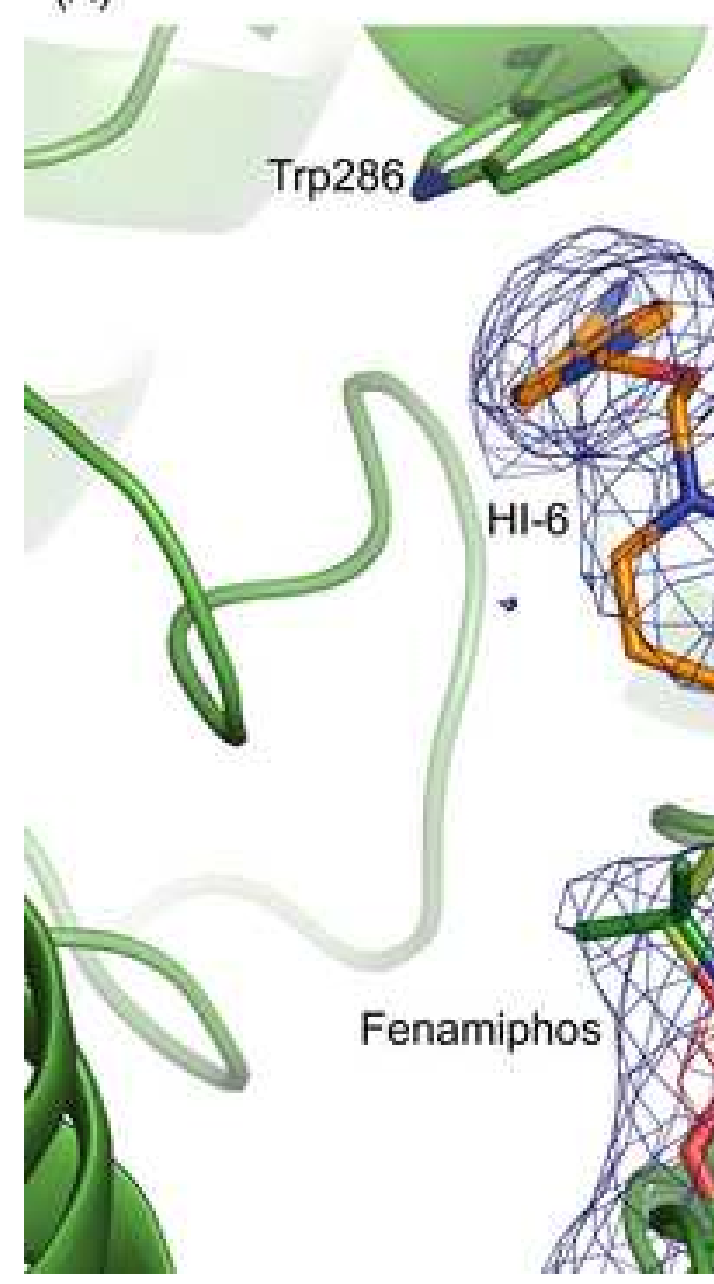

(B)

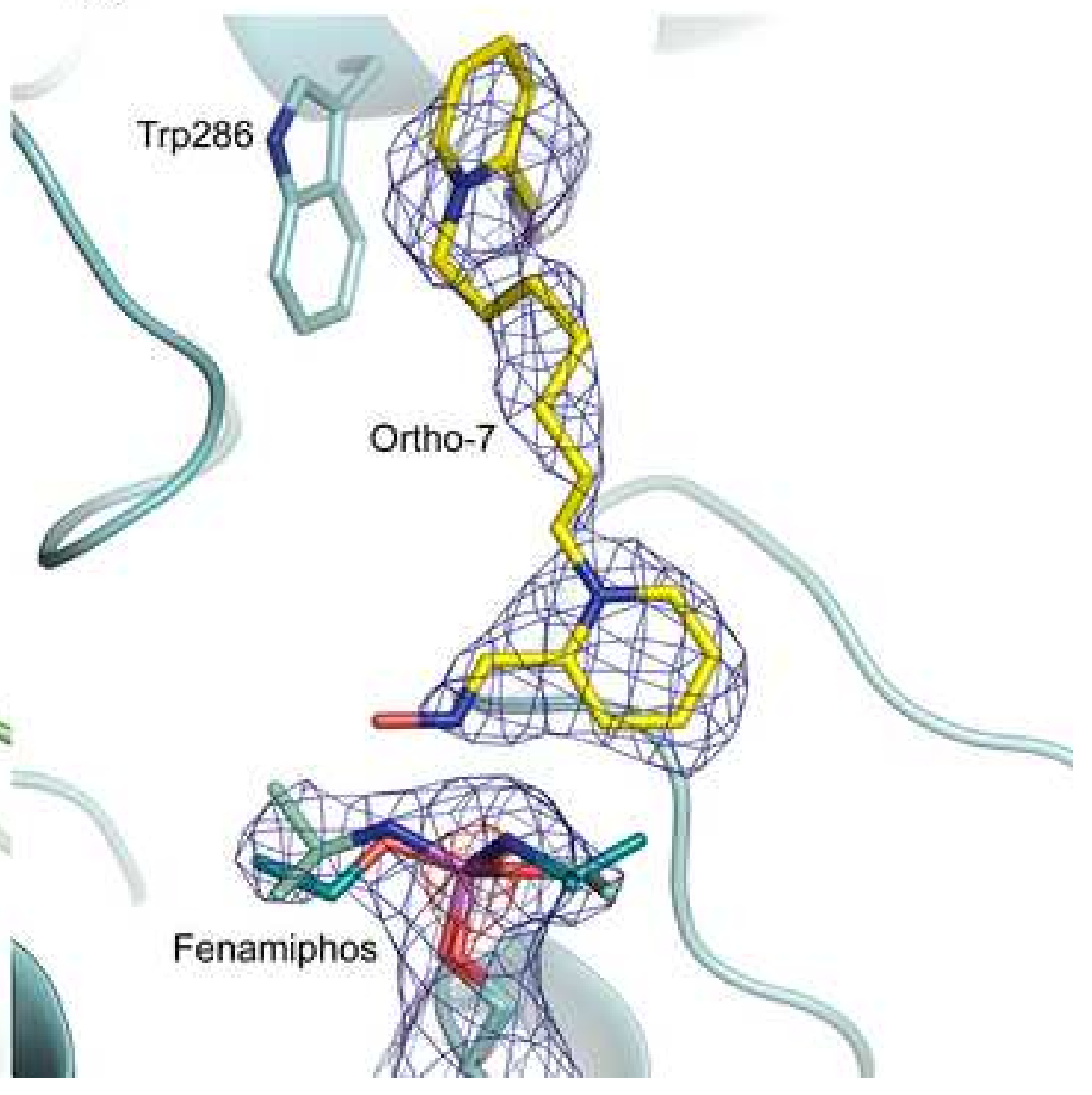




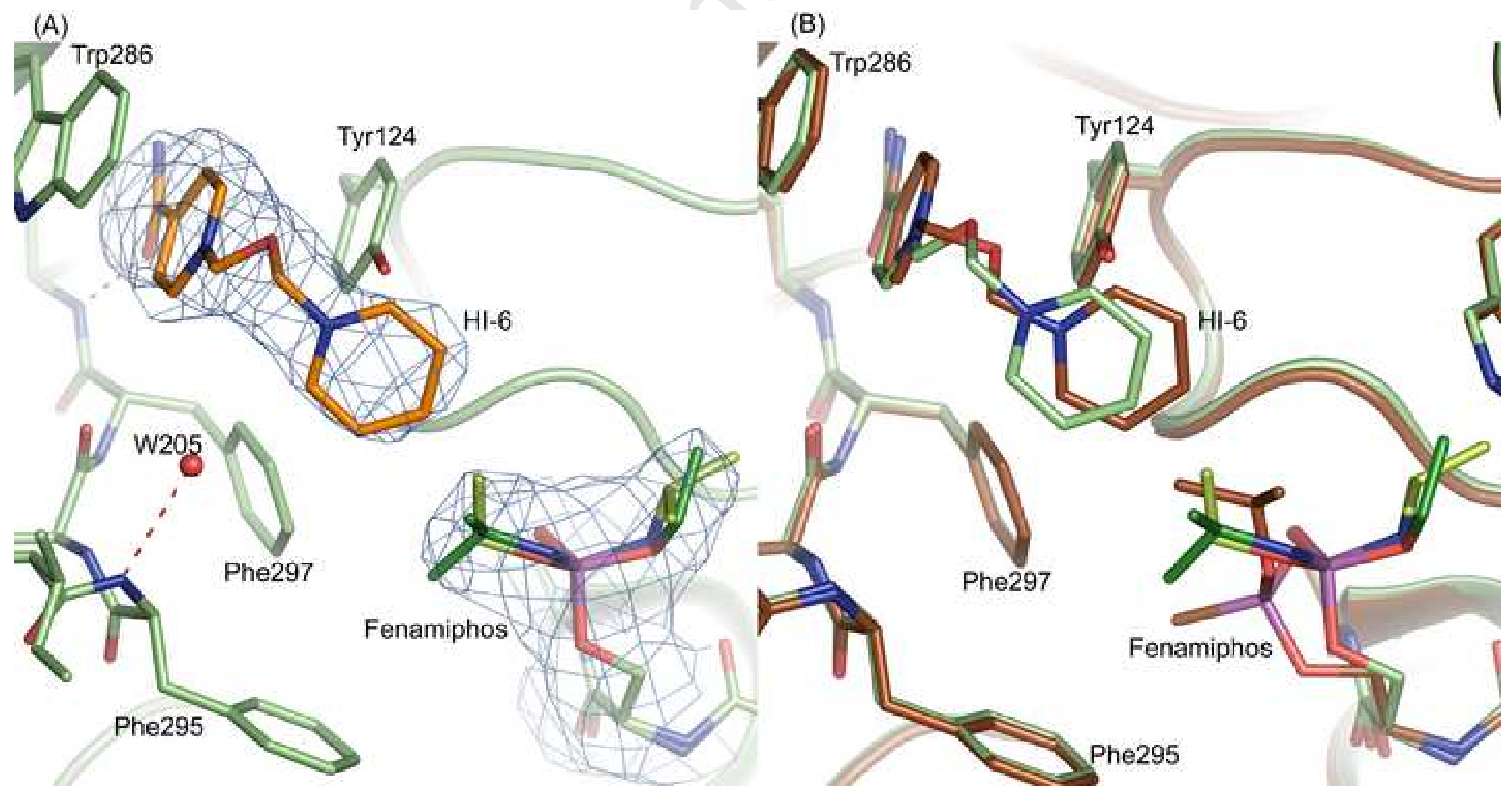


(A)

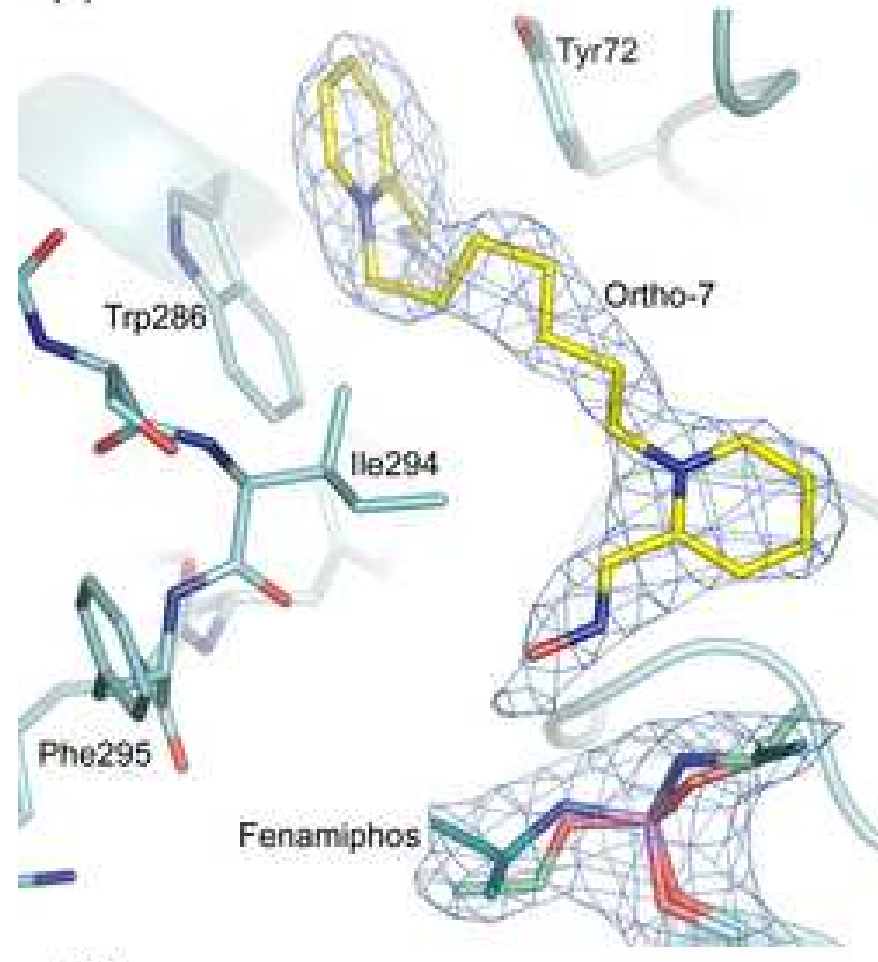

(C)
(B)

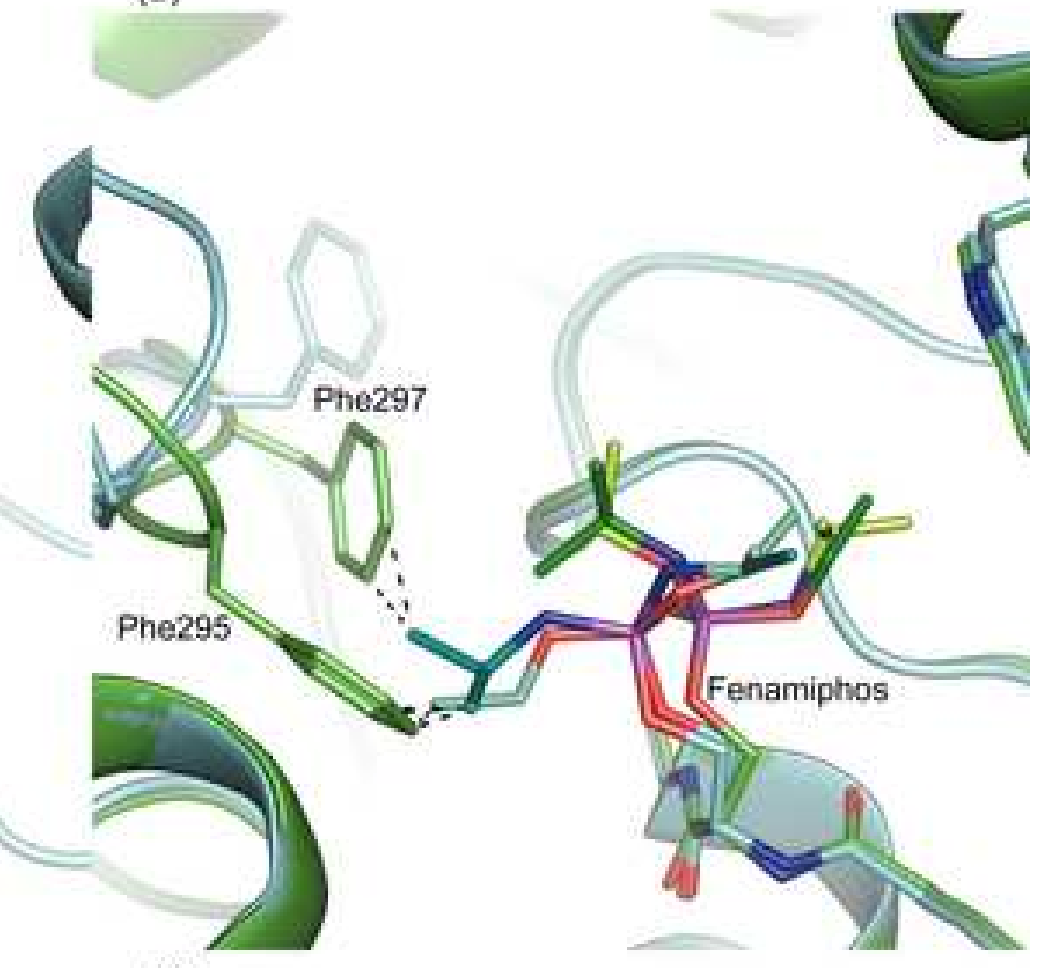

(D)

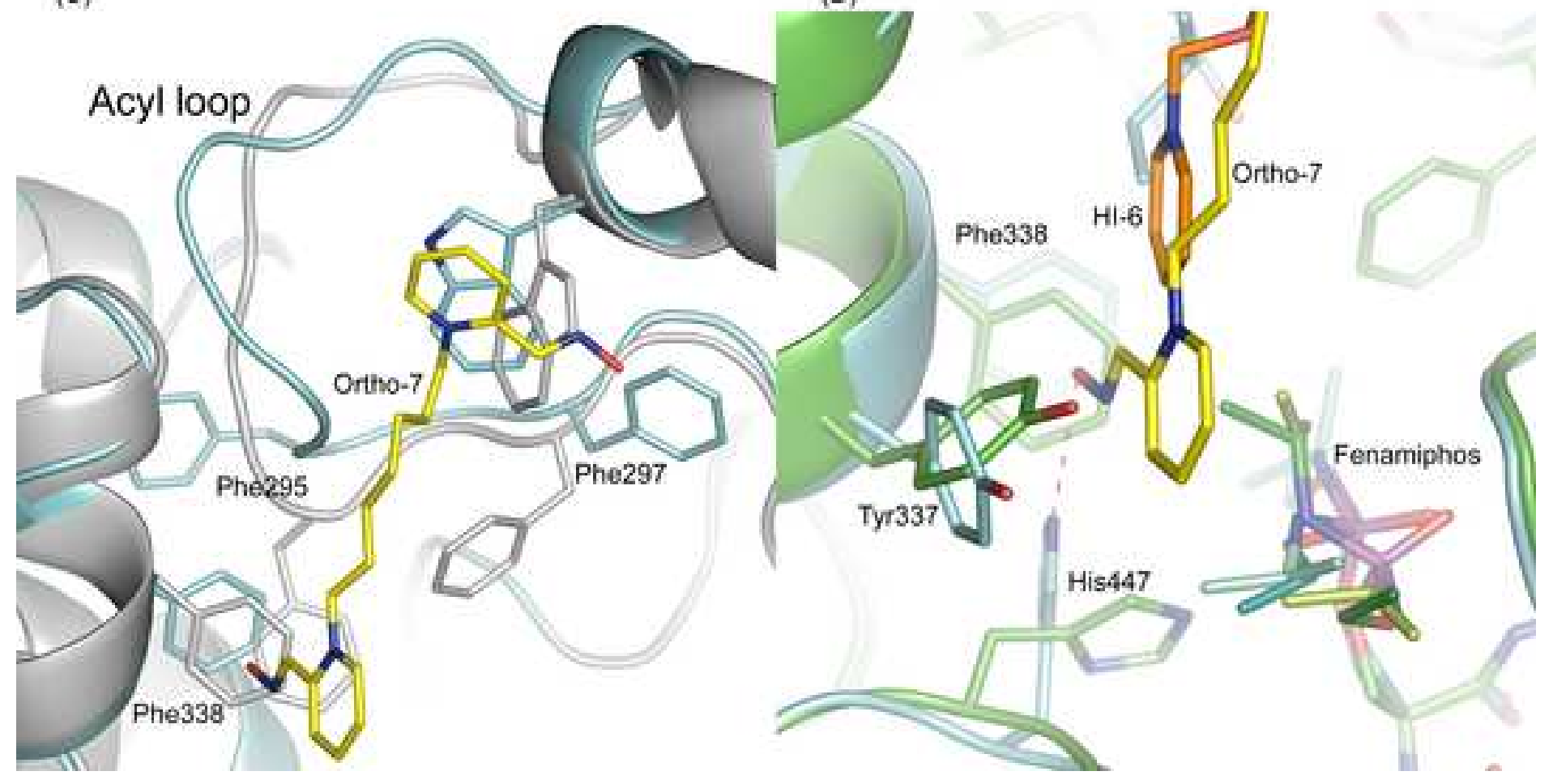




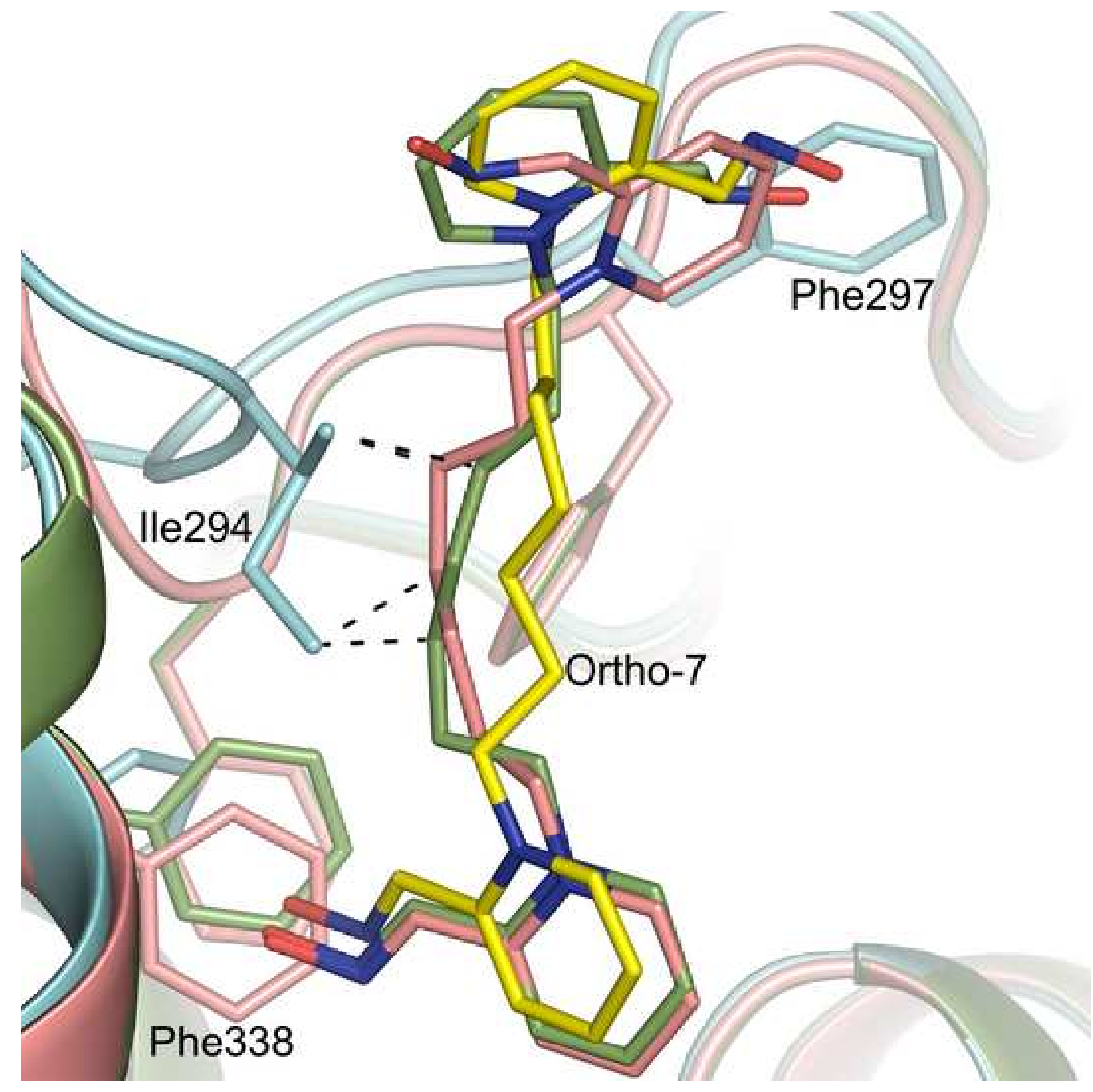

Page 30 of 39

Phe338

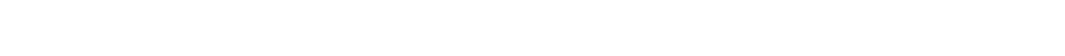

-294

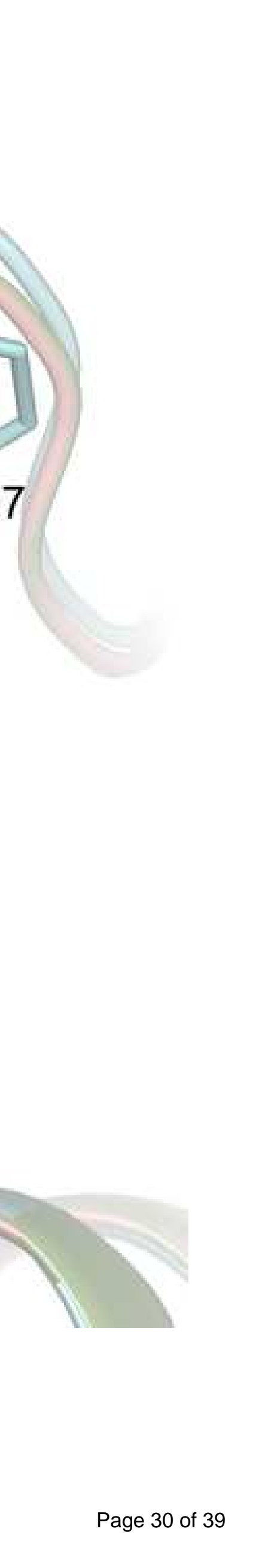




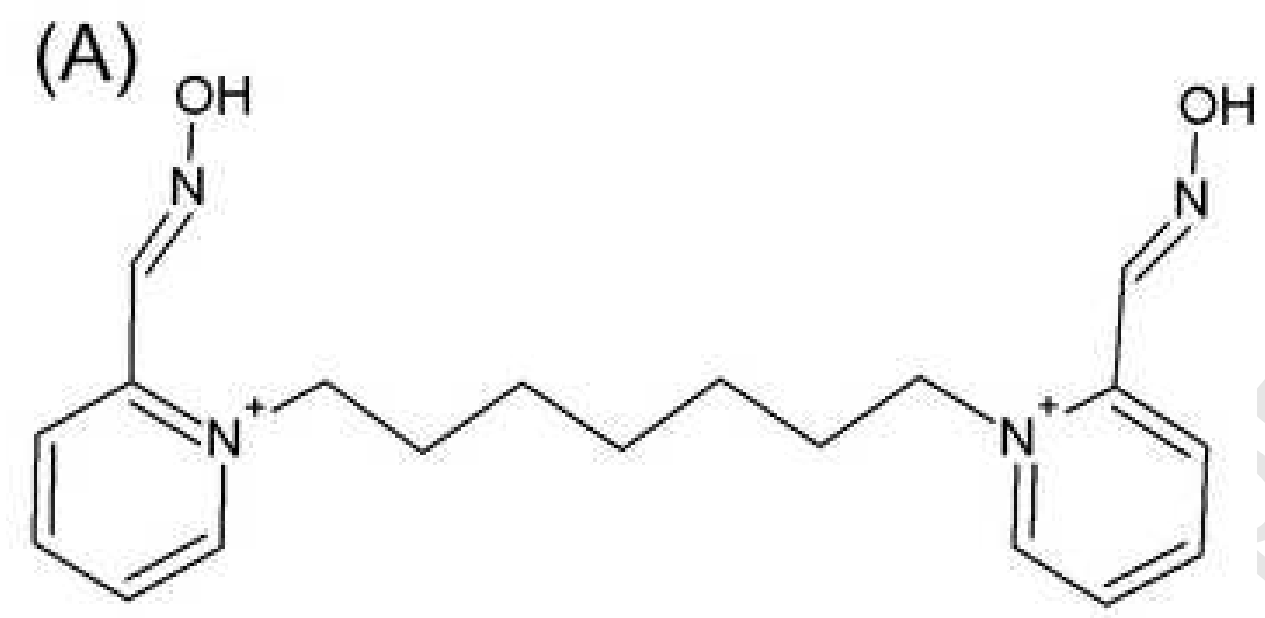

(B) $\mathrm{OH}$

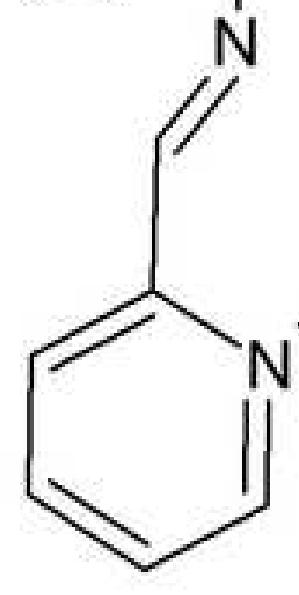

(C)<smiles>[3H]COC[NH+]=CC</smiles>

$\mathrm{H}_{3} \mathrm{C}$

$\mathrm{H}_{3} \mathrm{C}$

$\mathrm{H}_{2} \mathrm{~N}$

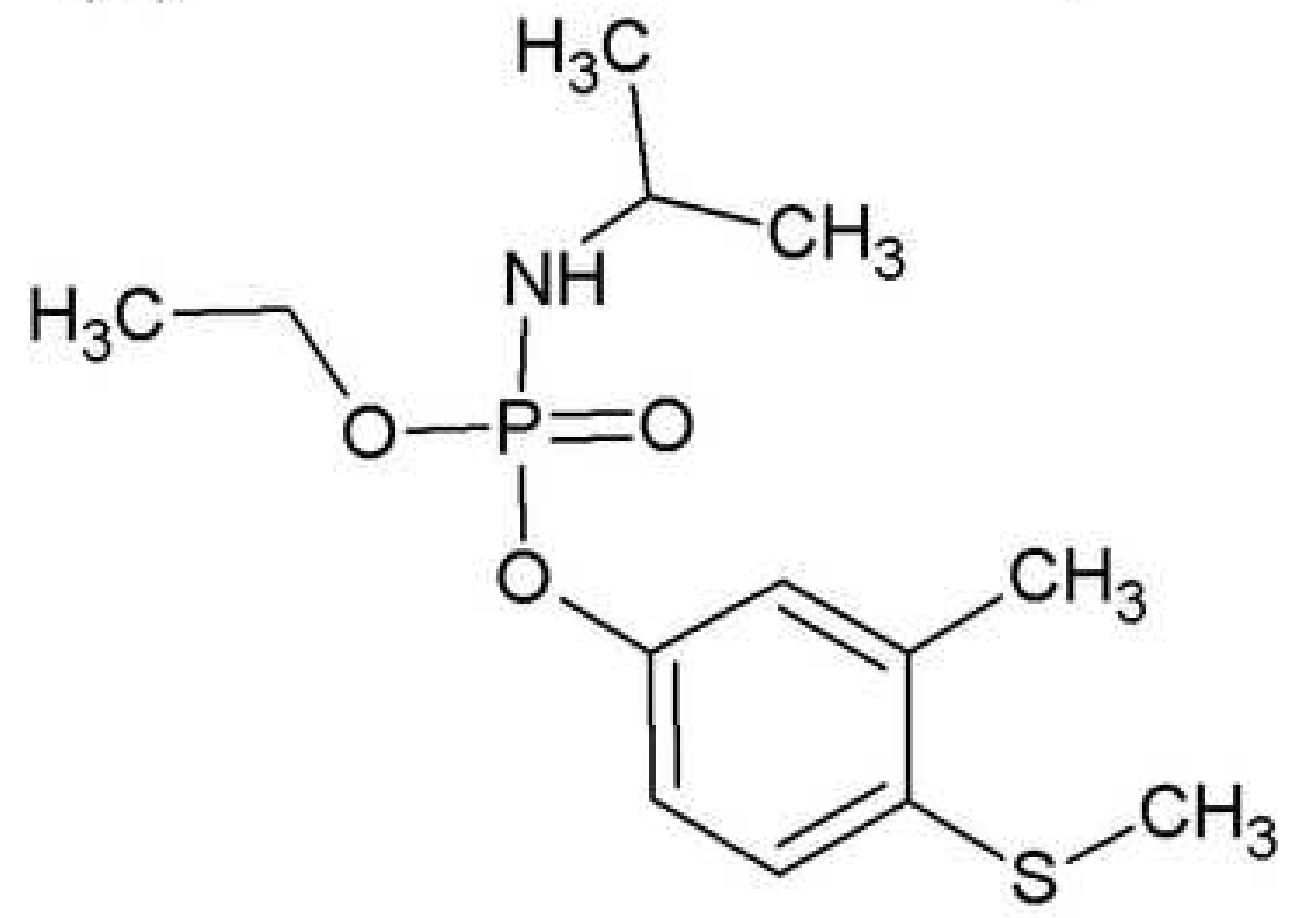

Page 31 of 39 


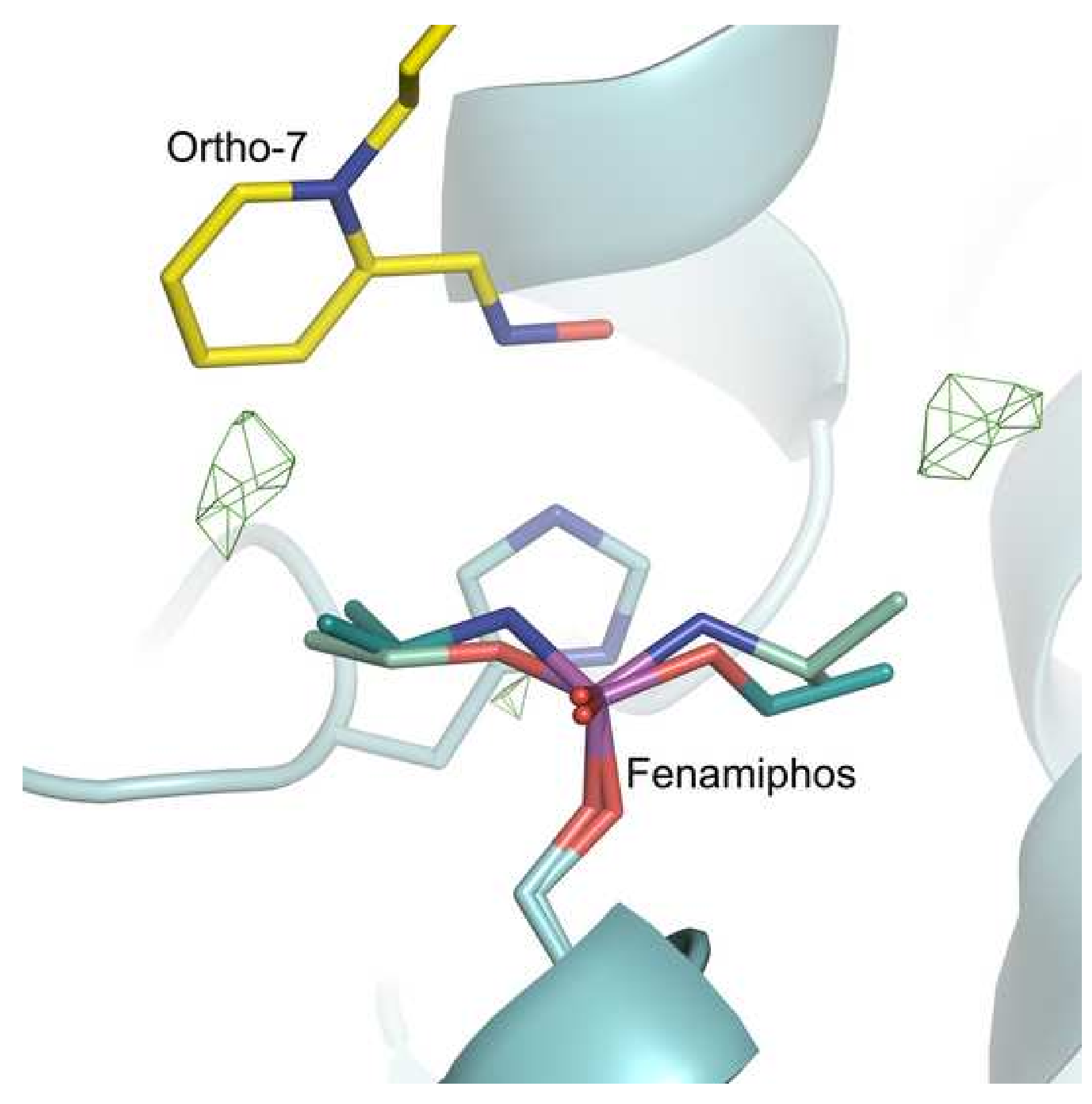

Page 32 of 39

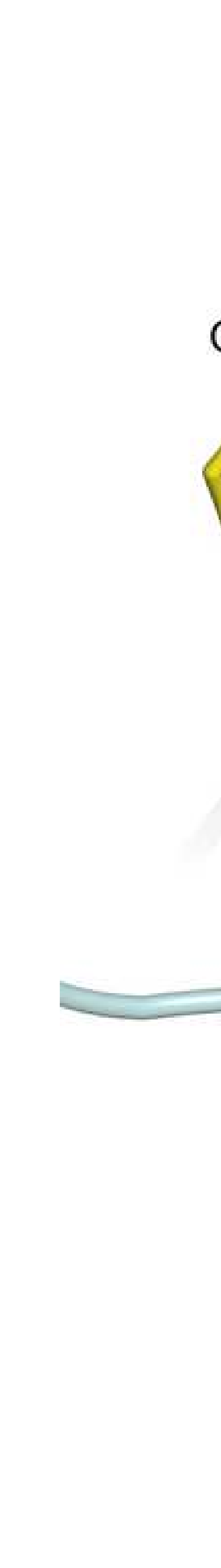

(n)

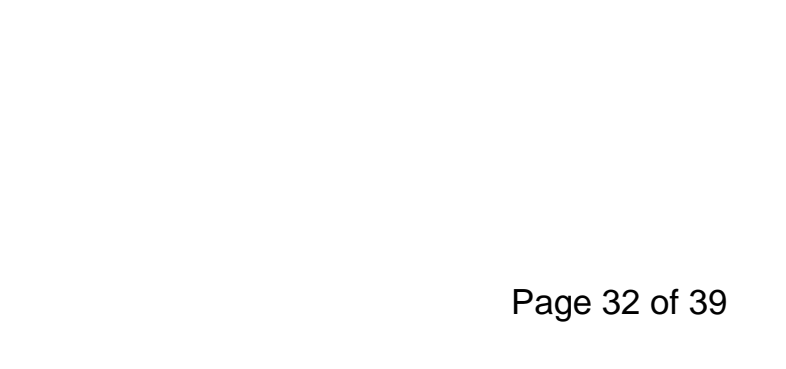

s

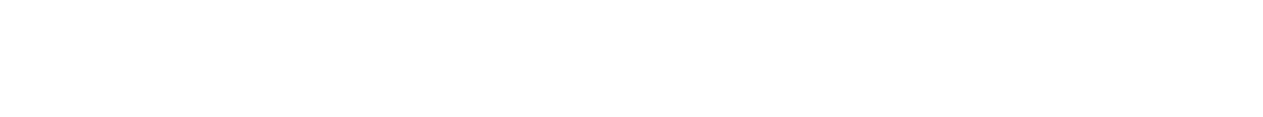

\section{Fenamiphos}

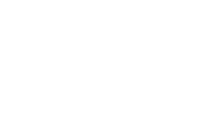


(A)

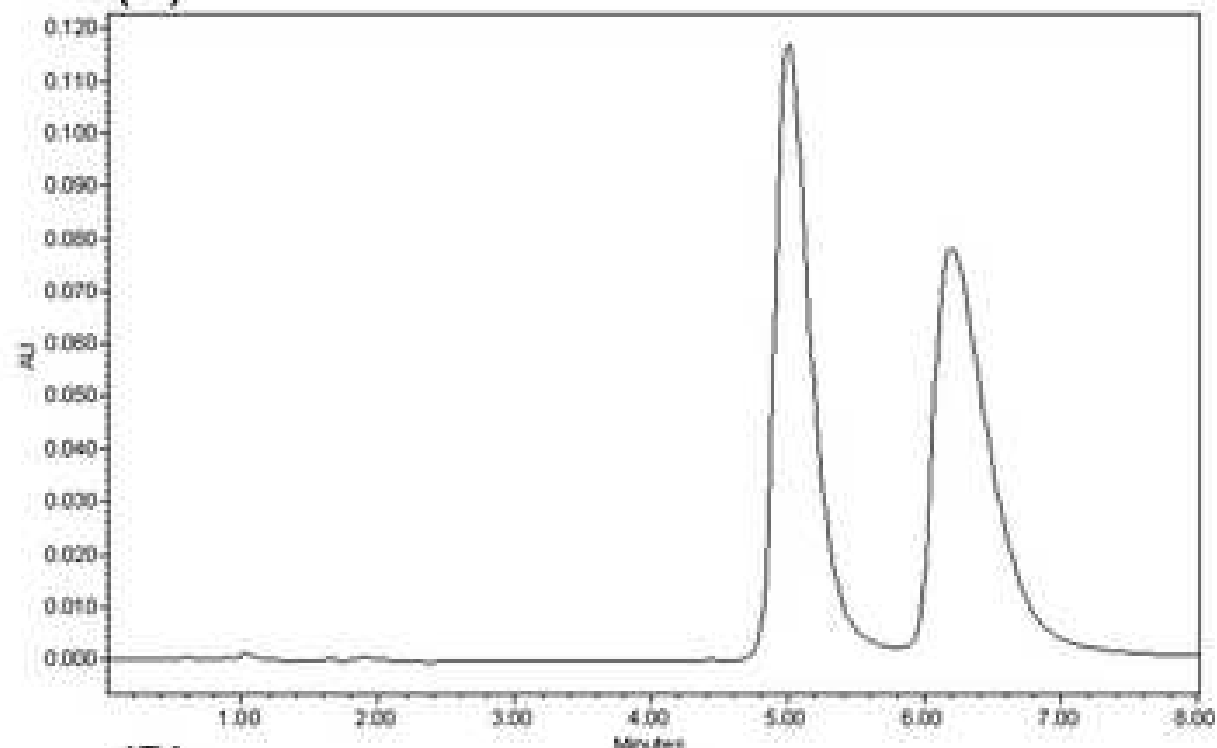

(B)

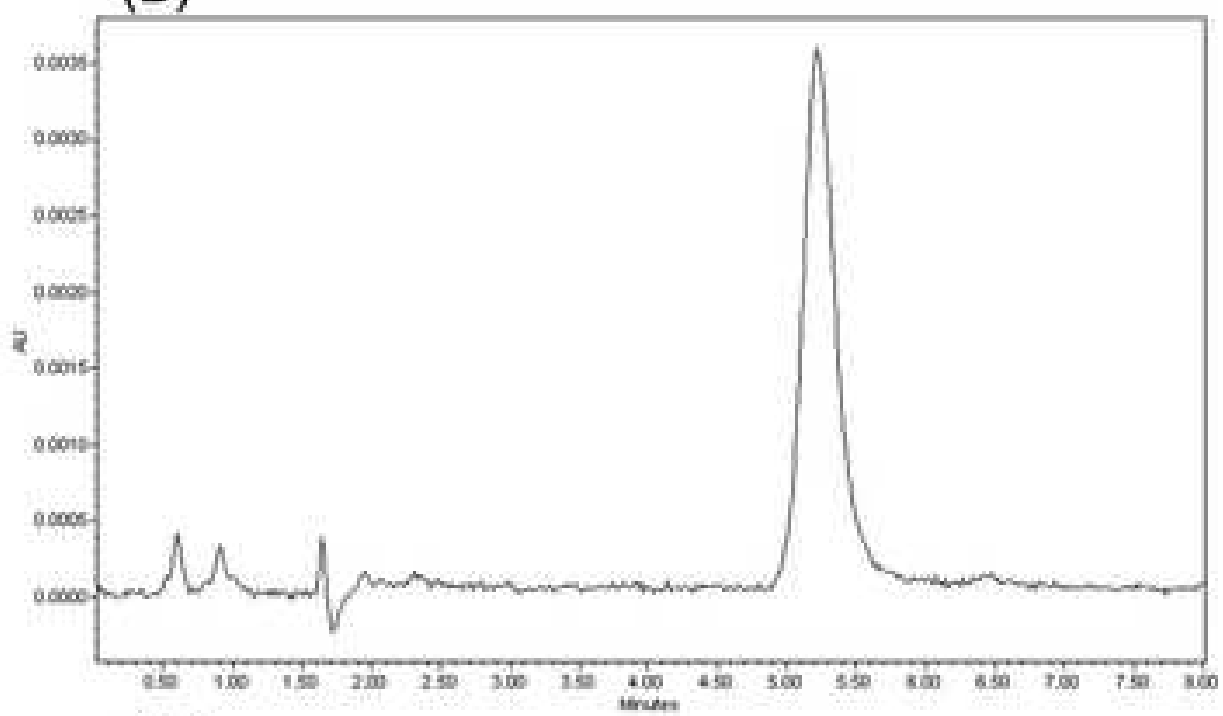

(C)

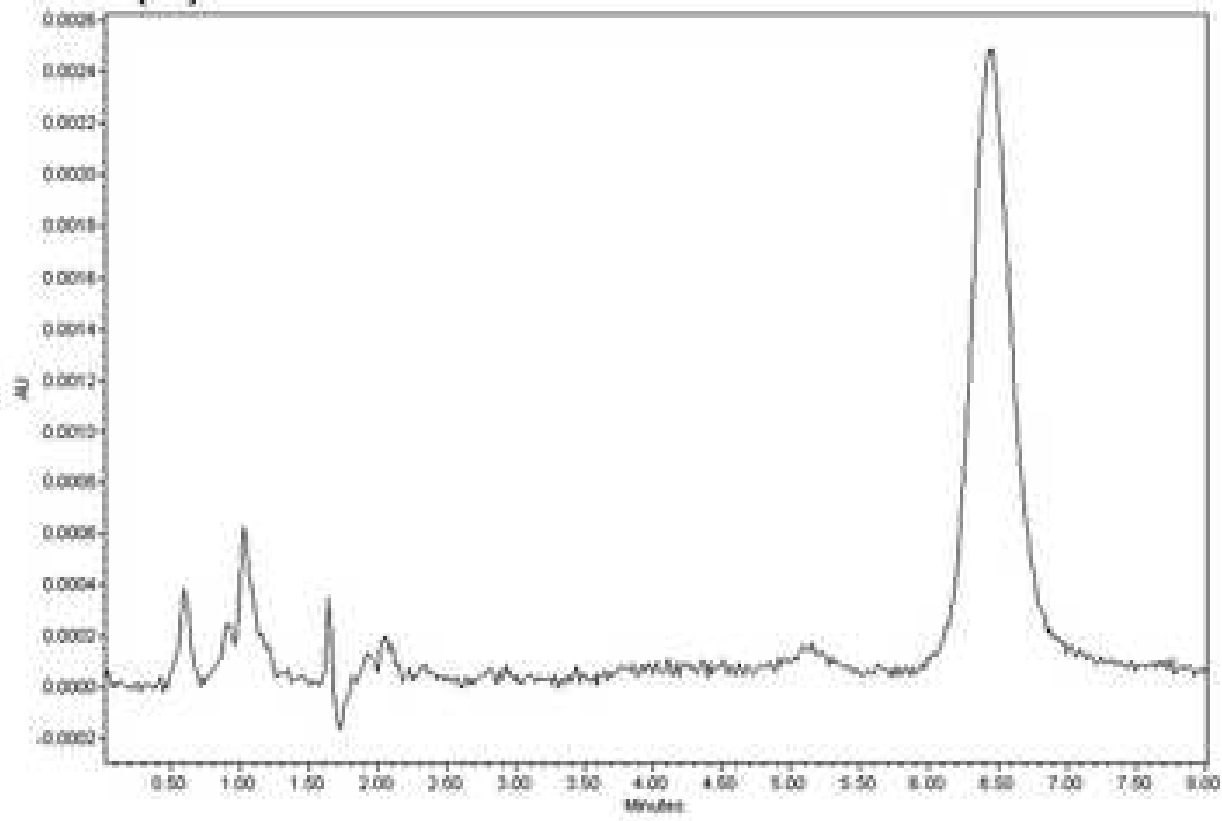




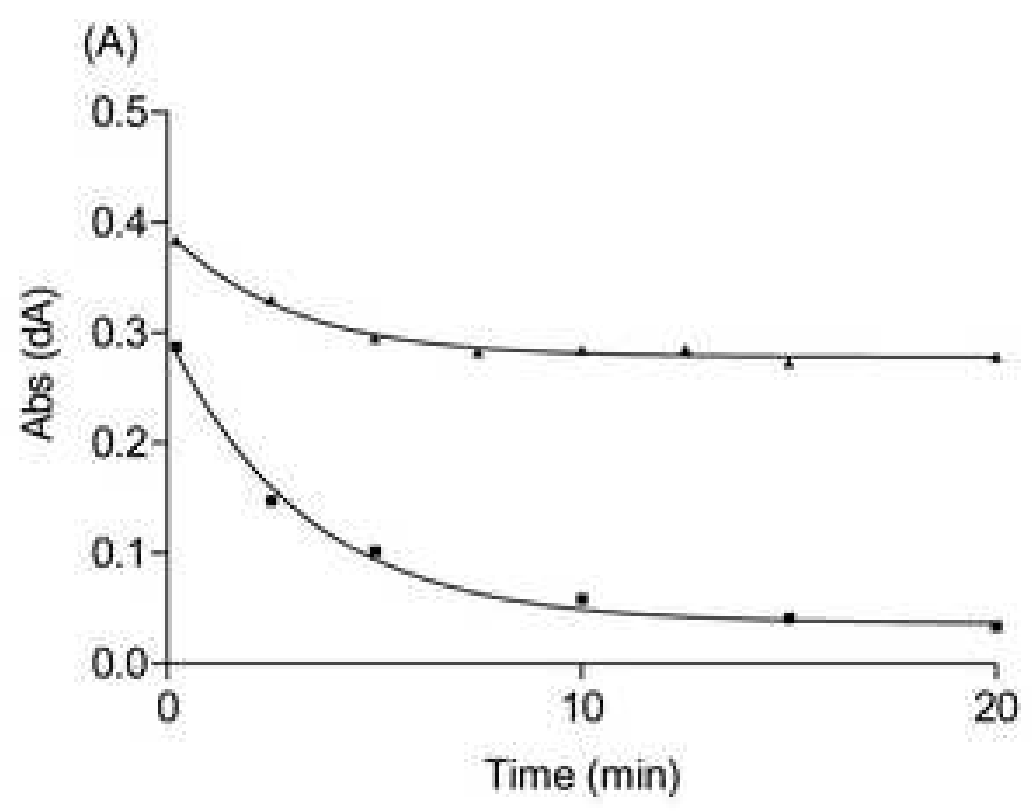

(B)

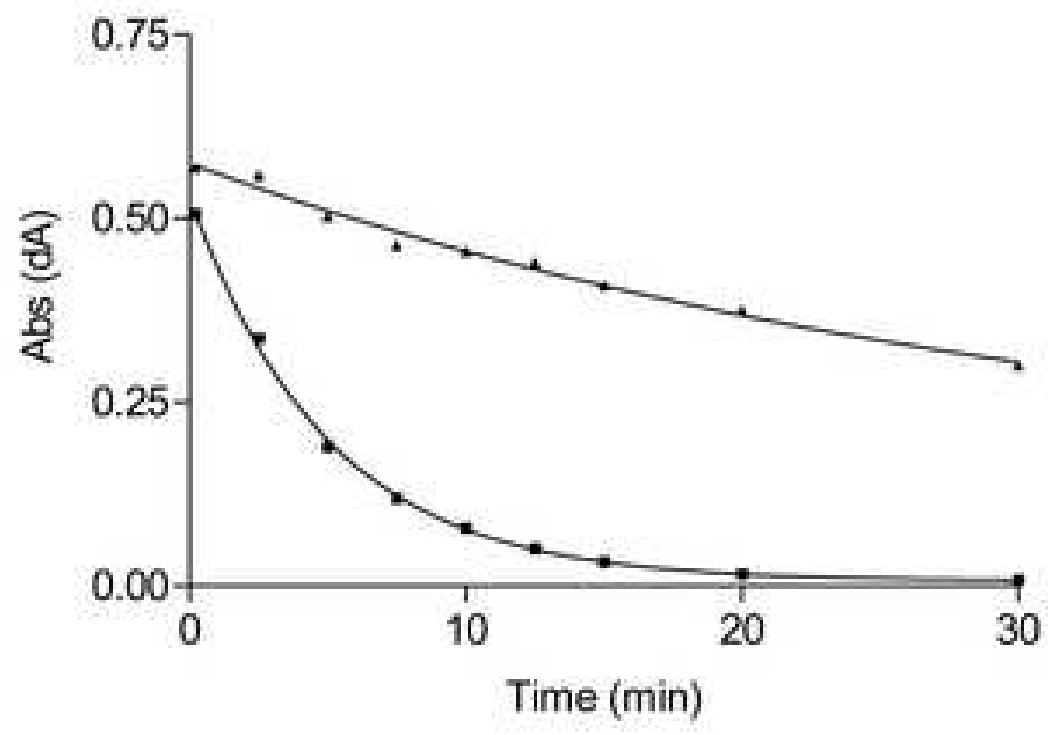

(C)

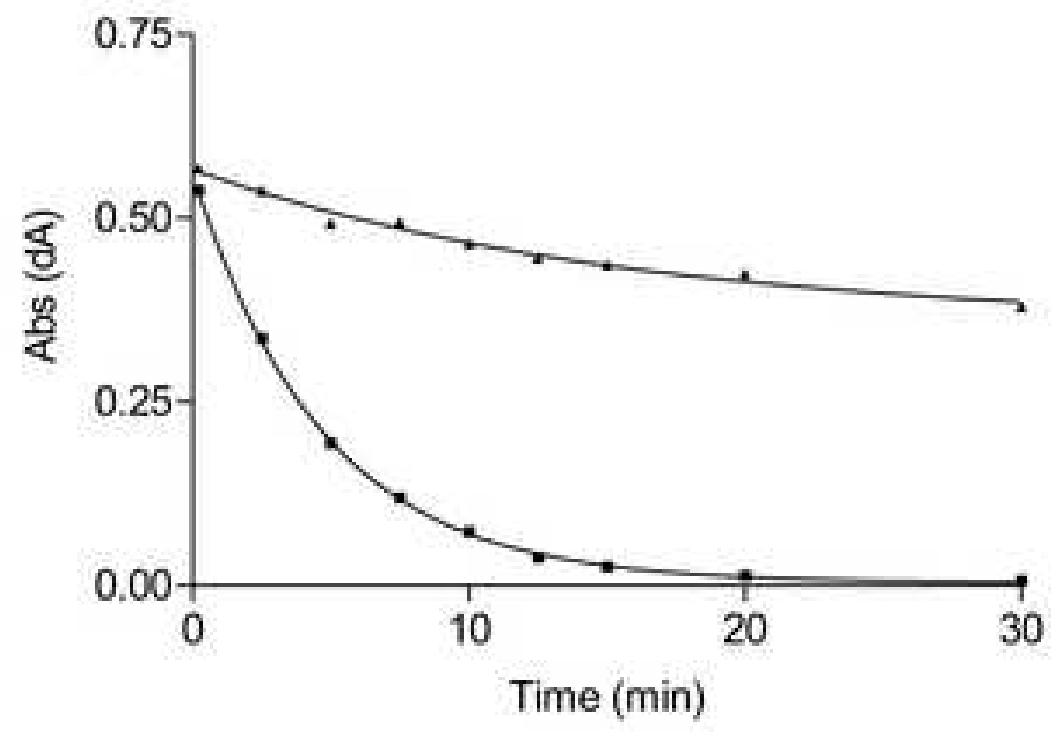




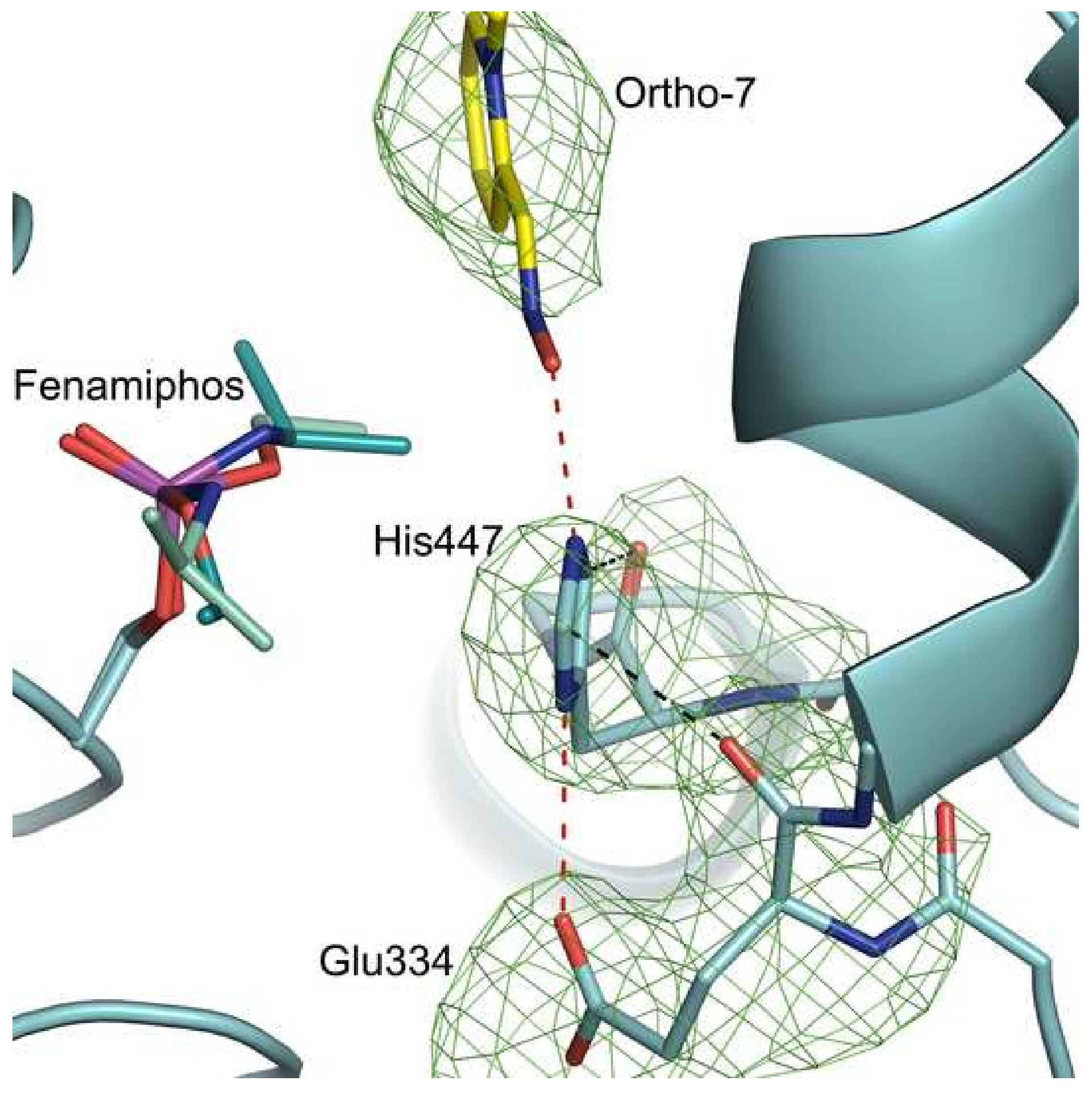




\section{D}

Fenamiphos
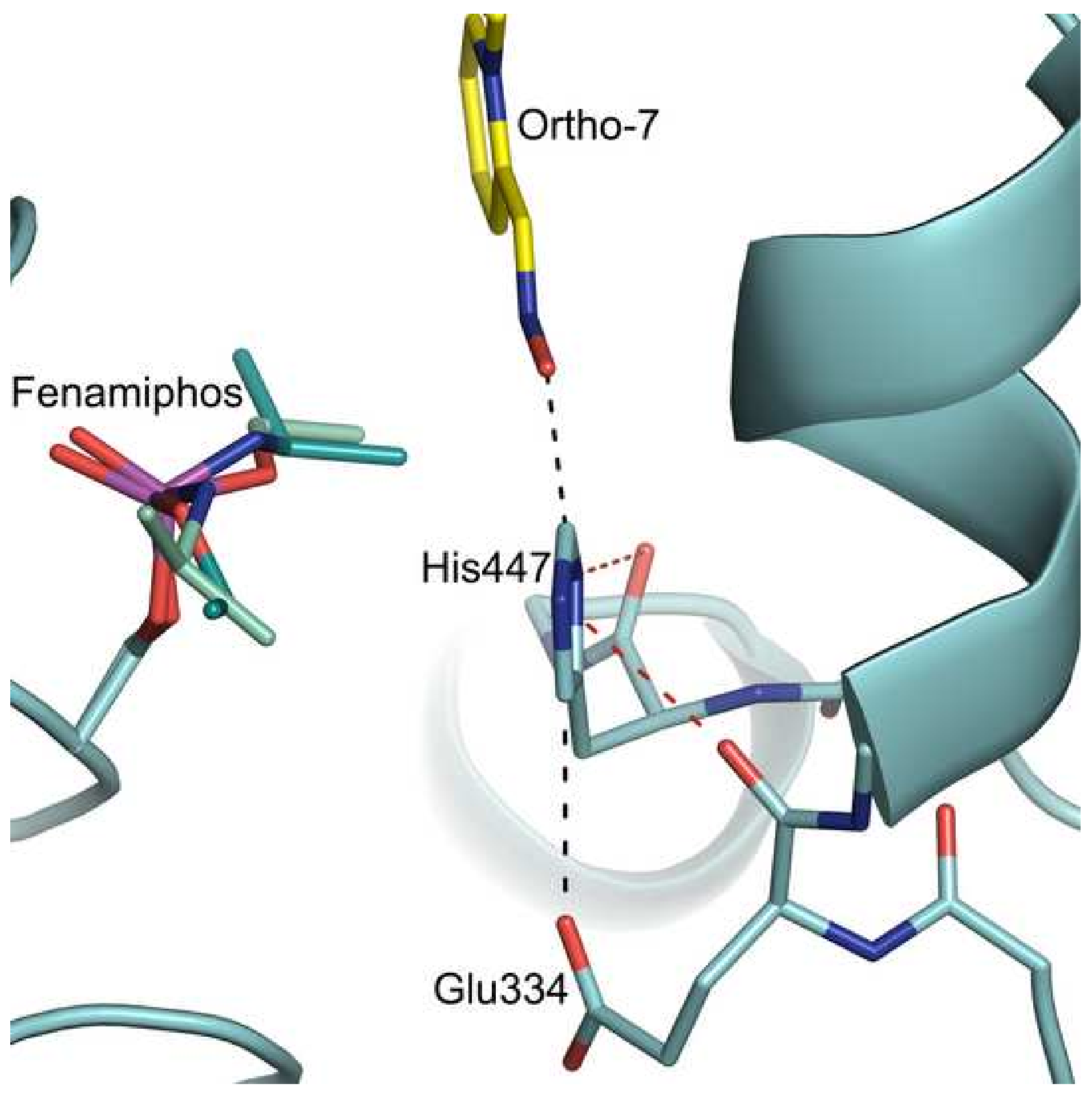


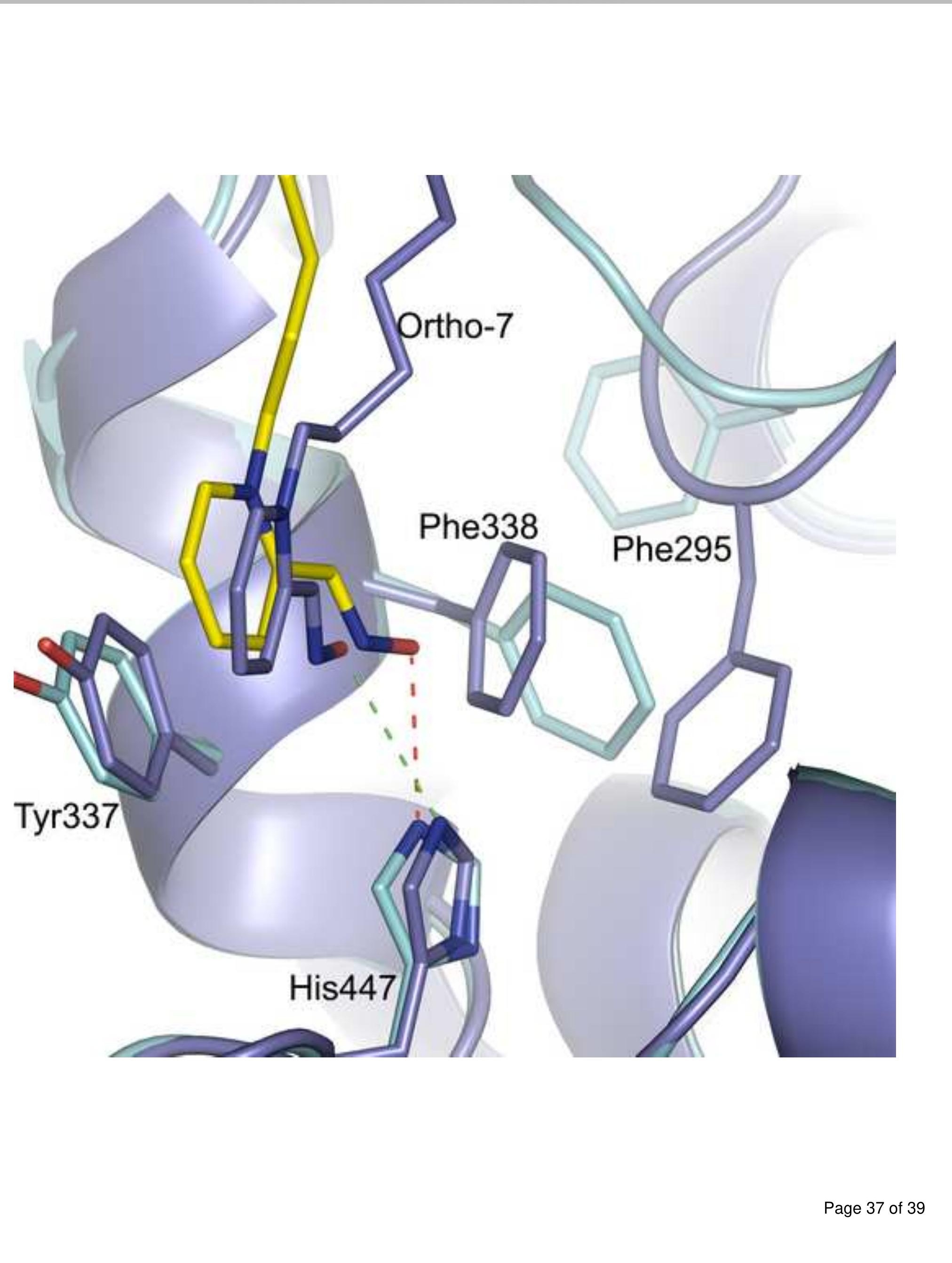

Phe295

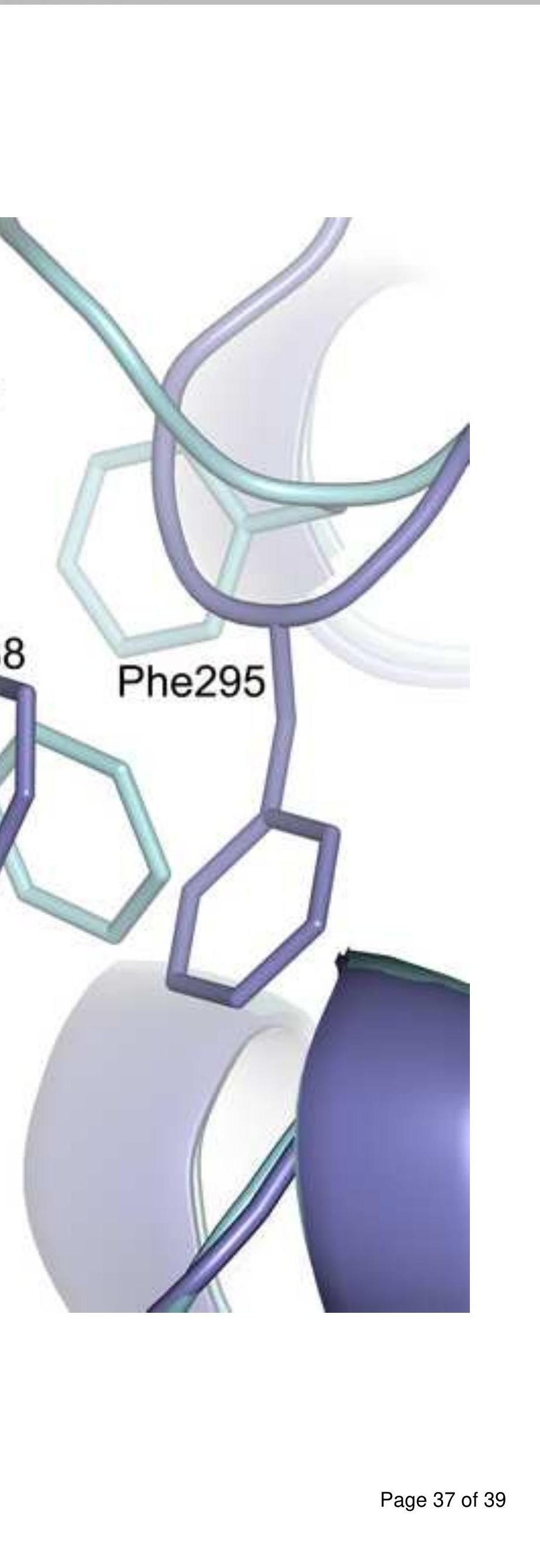


The Glu334-His447-Ortho-7 triad can function as an activator by deprotonating the hydroxyl oxygen of the oxime prior to reactivation of organophosphorus-inhibited acetylcholinesterase. 